\title{
Influence of Proteome Profiles and Intracellular Drug Exposure on Differences in CYP Activity in Donor-Matched Human Liver Microsomes and Hepatocytes
}

\author{
Christine Wegler, Pär Matsson, Veronica Krogstad, Jozef Urdzik, Hege Christensen, \\ Tommy B. Andersson, and Per Artursson*
}

Cite This: Mol. Pharmaceutics 2021, 18, 1792-1805

Read Online

ACCESS | Lلll Metrics \& More | 回 Article Recommendations ｜ sl Supporting Information

ABSTRACT: Human liver microsomes (HLM) and human hepatocytes $(\mathrm{HH})$ are important in vitro systems for studies of intrinsic drug clearance $\left(\mathrm{CL}_{\text {int }}\right)$ in the liver. However, the $\mathrm{CL}_{\text {int }}$ values are often in disagreement for these two systems. Here, we investigated these differences in a side-by-side comparison of drug metabolism in HLM and HH prepared from 15 matched donors. Protein expression and intracellular unbound drug concentration $\left(\mathrm{Kp}_{\mathrm{uu}}\right)$ effects on the $\mathrm{CL}_{\text {int }}$ were investigated for five prototypical probe substrates (bupropion-CYP2B6, diclofenac-CYP2C9, omeprazole-CYP2C19, bufuralol-CYP2D6, and midazolamCYP3A4). The samples were donor-matched to compensate for inter-individual variability but still showed systematic differences in

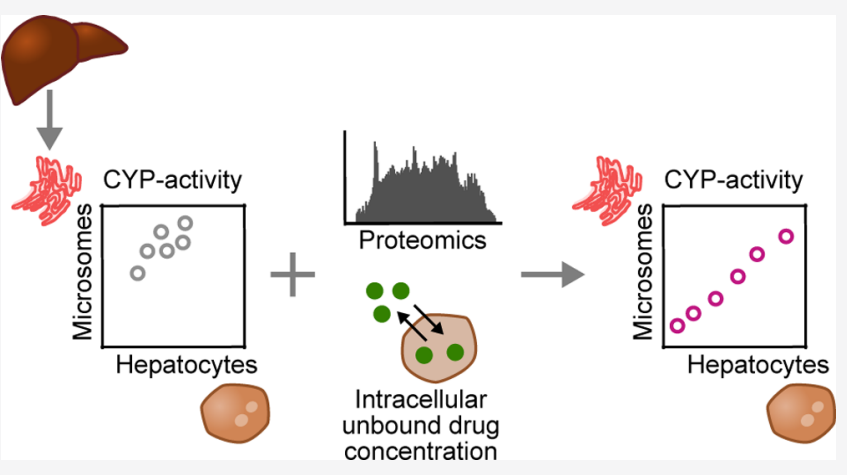
$\mathrm{CL}_{\text {int }}$. Global proteomics analysis outlined differences in HLM from $\mathrm{HH}$ and homogenates of human liver (HL), indicating variable enrichment of ER-localized cytochrome P450 (CYP) enzymes in the HLM preparation. This suggests that the HLM may not equally and accurately capture metabolic capacity for all CYPs. Scaling $\mathrm{CL}_{\text {int }}$ with CYP amounts and $\mathrm{Kp}_{\text {uu }}$ could only partly explain the discordance in absolute values of $\mathrm{CL}_{\text {int }}$ for the five substrates. Nevertheless, scaling with CYP amounts improved the agreement in rank order for the majority of the substrates. Other factors, such as contribution of additional enzymes and variability in the proportions of active and inactive CYP enzymes in HLM and HH, may have to be considered to avoid the use of empirical scaling factors for prediction of drug metabolism.

KEYWORDS: human liver hepatocytes, human liver microsomes, drug clearance, protein quantification, intracellular unbound drug concentration

\section{INTRODUCTION}

Intrinsic hepatic drug clearance influences drug bioavailability and exposure. To investigate this, in vitro models are often used during drug discovery and development. The two most commonly used models are isolated hepatocytes and liver microsomes. $^{1-9}$ Isolated hepatocytes are the gold standard because these cells capture most of the factors influencing hepatic intrinsic clearance $\left(\mathrm{CL}_{\text {int }}\right)$. They are used in various configurations to quantify metabolic activity as well as uptake and efflux transport of drugs and metabolites. ${ }^{10}$ However, liver microsomes are usually the first screening tool in studies of metabolic clearance because of their low cost and ease of access. ${ }^{11}$ Microsomes are derived by subcellular fractionation, with enrichment of the endoplasmic reticulum (ER). ${ }^{12}$ Many membrane-bound drug metabolizing enzymes are located in the ER, including cytochrome P450s (CYPs) and many UDPglucuronosyltransferases (UGTs). Different results are often obtained from the hepatocytes and microsomes, ${ }^{1,2,7,13,14}$ but the reasons for these differences are not fully understood.
Mass spectrometry-based proteomics is increasingly used to investigate the protein content of the various drug metabolizing enzymes in microsomal preparations. We and others have shown that CYP and UGT enzymes are not enriched to the expected degree in subcellular fractions compared to the unfractionated homogenate. ${ }^{15,16}$ Large amounts of the ERassociated proteins are lost in the early fractionation steps, ${ }^{15,17}$ and the microsomes contain proteins from organelles other than the ER. ${ }^{18,19}$ Despite these studies on the protein composition of microsomes, no comprehensive analyses have compared the proteomes of liver microsomes, liver homogenates, and hepatocytes from the same donor. These analyses

Received: January 26, 2021

Revised: March 2, 2021

Accepted: March 3, 2021

Published: March 19, 2021 
would show the relative impact of variability from the fractionation process and from inter-individual variation. Furthermore, the effect of the variable degree of microsomal protein enrichment on the microsomal metabolic activity has not been extensively investigated.

In contrast to microsomes, hepatocytes have an intact plasma membrane barrier that drug compounds must permeate in order to be metabolized by the intracellular phase I and II enzymes. For low-permeability drugs, the passage across the cell membrane can be rate limiting as active transport mechanisms can both facilitate and limit the cellular drug accumulation. The extent of drug metabolism in hepatocytes can be greatly influenced by the intracellular concentration of unbound drug, that is, how much drug is present inside the hepatocyte in accessible form. ${ }^{20}$ We recently observed that differences between biochemical and cellular potency assays could be bridged by taking into account the intracellular unbound drug concentration (expressed as intracellular bioavailability). ${ }^{21}$ We also found that over-prediction of timedependent CYP inhibition could be resolved by incorporating the intracellular unbound drug concentration into a mechanistic static model. ${ }^{22}$ Furthermore, the intracellular unbound concentration can be used as a scaling factor to explain differences in CYP enzyme inhibition in both microsomes and hepatocytes. $^{23}$

In this study, we investigated the discordance in $\mathrm{CL}_{\text {int }}$ between microsomes and hepatocytes for certain drugs. We (1) considered the influence of inter-individual variability by studying the metabolic clearance of five commonly used probe drugs for CYP activity in 15 donor-matched human liver microsomes (HLM) and hepatocytes ( $\mathrm{HH})$. We also compared the protein composition of human liver (HL) homogenates, HLM, and HH from the same donors, to (2) elucidate whether the specific CYP amount in the two systems explained the differences in drug metabolism. Finally, (3) we investigated whether the concept of intracellular unbound drug concentration (as measured by $\mathrm{Kp}_{\mathrm{uu}}$ ) could explain the differences in metabolic clearance.

\section{METHODS}

HL Tissue. Excess tissue from HL resection surgery was obtained from the Department of Surgery, Uppsala University Hospital, Sweden. All 15 donors provided informed consent, in agreement with the approval from the Uppsala Regional Ethical Review Board (Ethical Approval no. 2009/028). The donors had a mean age of 65 years (ranging from 39 to 79 years) and a mean BMI of $26.4 \mathrm{~kg} / \mathrm{m}^{2}$ (ranging from 20.1 to $32.9 \mathrm{~kg} / \mathrm{m}^{2}$ ). Donor characteristics are summarized in Table S1.

Small pieces were immediately snap-frozen in methyl butane on dry ice and ethanol and stored at $-150{ }^{\circ} \mathrm{C}$. A larger piece was perfused with HypoThermosol FRS to remove the blood and kept on ice for at most $2 \mathrm{~h}$ prior to isolation of hepatocytes.

Hepatocyte Isolation, Cryopreservation, and Thawing. Primary hepatocytes $(\mathrm{HH})$ were isolated individually from each donor based on a two-step collagenase perfusion technique, as previously described. ${ }^{24}$ Isolated $\mathrm{HH}$ were resuspended and frozen at $10 \times 10^{6}$ viable cells $/ \mathrm{mL}$ in either KaLy-Cell medium (KaLy-Cell) or CryoStor CS10 (BioLife Solutions) with $10 \%$ FBS, as previously described. ${ }^{25}$ Cells were thawed at $37{ }^{\circ} \mathrm{C}$ for approximately $2 \mathrm{~min}$, and dead cells were separated by centrifugation at $100 \mathrm{~g}$ for $10 \mathrm{~min}$ at room temperature in Dulbecco's modified Eagle medium (Gibco) with 30\% isotonic Percoll (GE Healthcare), prior to use.

Subcellular Fractionation and Microsomal Preparation. HLM were prepared from snap-frozen liver tissue pieces from each of the 15 donors, based on a previously described protocol. $^{26,27}$ Briefly, liver pieces were thawed on ice and homogenized using a Potter-Elvehjem pestle at $2000 \mathrm{rpm}$ in sucrose buffer ( $0.32 \mathrm{M}$ sucrose, $10 \mathrm{mM}$ Trisma base, $0.37 \mathrm{mg} /$ $\mathrm{mL}$ EDTA, and complete mini protease inhibitor cocktail, $\mathrm{pH}$ 7.4). For each donor, an aliquot of the HL homogenate was collected, frozen, and saved for proteomics analysis. The remaining liver homogenate was centrifuged for $10 \mathrm{~min}$ at $7400 \mathrm{~g}, 4{ }^{\circ} \mathrm{C}$. The supernatant was transferred to a new tube, and the obtained pellet was collected, frozen, and saved for proteomics analysis. The supernatant was further centrifuged for $60 \mathrm{~min}$ at $104,000 \mathrm{~g}, 4{ }^{\circ} \mathrm{C}$, and the remaining pellet was resuspended in a buffer containing $0.25 \mathrm{M}$ sucrose, $10 \mathrm{mM}$ HEPES, and $0.8 \mathrm{mg} / \mathrm{mL}$ EDTA ( $\mathrm{pH} 7.4)$. The resuspended microsomal fraction was frozen and kept at $-80{ }^{\circ} \mathrm{C}$. Protein yields after tissue homogenization and microsomal preparation are shown in Table 1 .

Table 1. Protein Yield and Protein Amount Used in Incubations

\begin{tabular}{ccc} 
& median & range \\
Yield Homogenization of Liver Tissue & \\
Yield Microsomal Preparation & 97.2 & $56.4-116.9$ \\
total protein per g liver $(\mathrm{mg} / \mathrm{g})$ & $10.8-80.3$ \\
Total Protein in Incubations & \\
total microsomal protein per g liver $(\mathrm{mg} / \mathrm{g})$ & 0.25 & \\
total microsomal protein $(\mathrm{mg})$ & 0.84 & $0.23-1.68$ \\
hepatocytes, $10^{6}$ cells $(\mathrm{mg})$ & & \\
\hline
\end{tabular}

Protein Quantification. HL, HH, HLM, and the pellet from the first centrifugation ("discard pellet" obtained from 10 min centrifugation of the homogenate at $7400 \mathrm{~g}, 4{ }^{\circ} \mathrm{C}$ ) were lysed in $100 \mathrm{mM}$ Tris- $\mathrm{HCl}$ buffer, $\mathrm{pH} 7.4$, containing $2 \%$ SDS and $50 \mathrm{mM}$ DTT. Proteins were denatured at $95{ }^{\circ} \mathrm{C}$. Samples were prepared for proteomic analysis using the multi-enzyme digestion filter-aided sample preparation protocol, in which proteins are digested with LysC and trypsin. ${ }^{28}$ Protein and peptide amounts were determined based on tryptophan fluorescence. ${ }^{29}$ Peptides were separated on a reverse-phase EASY-spray LC column $\left(2 \mu \mathrm{m} \mathrm{C}_{18}\right.$ particles, $50 \mathrm{~cm} \times 75 \mu \mathrm{m}$ inner diameter; Thermo Fisher Scientific) using a $2 \mathrm{~h}$ acetonitrile gradient in $0.1 \%$ formic acid at a flow rate of $300 \mathrm{~nL} / \mathrm{min}$. The LC was coupled to a Q Exactive HF mass spectrometer (Thermo Fisher Scientific) operating in a datadependent mode with survey scans at a resolution of 240,000, AGC target of $3 \times 10^{6}$, and maximum injection time of $20 \mathrm{~ms}$. The top 15 most abundant isotope patterns were selected from the survey scan with an isolation window of $1.4 \mathrm{~m} / z$ and fragmented with normalized collision energy (nCE) at 28.5. The MS/MS analysis was performed with a resolution of 15,000 , AGC target of $1 \times 10^{5}$, and maximum injection time of $60 \mathrm{~ms}$. The resulting MS data were processed with MaxQuant, ${ }^{30}$ in which proteins are identified by searching MS and MS/MS data of peptides against the human UniProtKB. Carboamidomethylation was set as fixed modification and protein discovery rates were specified as 0.01 . Spectral raw intensities were normalized with variance 
stabilization (vsn) $)^{31}$ and were subsequently used to calculate the protein concentrations using the Total Protein Approach. ${ }^{32}$

Intrinsic Clearance $\left(\mathrm{CL}_{\text {int }}\right)$ Measurements. Thawed $\mathrm{HH}$ from each of the 15 donors were resuspended to 1 million cells $/ \mathrm{mL}$ (protein amount in Table 1) in Hepatocyte Maintenance Medium (Lonza) containing $10 \mu \mathrm{g} / \mathrm{mL}$ insulin, $5.5 \mu \mathrm{g} / \mathrm{mL}$ transferrin, $5 \mathrm{ng} / \mathrm{mL}$ selenium, $0.1 \mu \mathrm{M}$ dexamethasone, $100 \mathrm{U} / \mathrm{mL}$ penicillin, and $100 \mu \mathrm{g} / \mathrm{mL}$ streptomycin. HLM, from each of the same 15 donors, were diluted to 0.5 $\mathrm{mg} / \mathrm{mL}$ (Table 1) in $100 \mathrm{mM}$ potassium phosphate buffer $\left(80 \% \mathrm{~K}_{2} \mathrm{HPO}_{4}\right.$ and $\left.20 \% \mathrm{KH}_{2} \mathrm{PO}_{4}, \mathrm{pH} 7.4\right)$. Metabolic activity reactions in HLM were initiated with $1 \mathrm{mM}$ NADPH. The $\mathrm{HH}$ and HLM were each incubated with probe drugs to monitor specific CYP enzyme activities. The drugs were added as a cocktail containing $1 \mu \mathrm{M}$ midazolam (CYP3A4/5), bufuralol (CYP2D6), bupropion (CYP2B6), and diclofenac (CYP2C9). In a separate incubation, CYP2C19 activity was monitored using $1 \mu \mathrm{M}$ of omeprazole. The total incubation time was 90 min at $37{ }^{\circ} \mathrm{C}$ with shaking at $350 \mathrm{rpm}$. Aliquots were taken after $0,5,10,15,20,30,60$, and $90 \mathrm{~min}$, and the reactions were stopped by mixing with ice-cold acetonitrile/water (60:40); $50 \mathrm{nM}$ warfarin was used as an internal standard. Compounds were quantified using UPLC-MS/MS, as described below. Clearance of the respective compound was determined using a substrate depletion method. ${ }^{4}$ Timepoint 0 represents $100 \%$ of the amount of the parent compound, and the remaining amount at each time point is converted to a percentage of this. The slope from the linear regression $(k)$ of log percentage remaining and incubation time was used to calculate the intrinsic clearance $\left(\mathrm{CL}_{\text {int }}\right)$

$$
\mathrm{CL}_{\mathrm{int}}=-k \times \frac{V_{\mathrm{inc}}}{P_{\mathrm{inc}}}
$$

or

$$
\mathrm{CL}_{\text {int, CYP }}=-k \times \frac{V_{\text {inc }}}{\mathrm{CYP}_{\text {inc }}}
$$

where $V_{\text {inc }}$ is the incubation volume, $P_{\text {inc }}$ is the amount of total protein in the HLM [as determined using the BCA Protein Assay Reagent Kit (Thermo Fisher Scientific Inc.)] or million cells in $\mathrm{HH}$ incubation, and $\mathrm{CYP}_{\text {inc }}$ is the amount (pmol) of specific probe CYP protein in the HH or HLM incubation determined, as described under the "Protein Quantification" section. Clearance in $\mathrm{HH}$ and HLM (both determined with million cells or total amount of protein- $-\mathrm{CL}_{\text {inthep }}$ and $\mathrm{CL}_{\text {int,mic }}$ - and with specific amount of probe CYP protein$\mathrm{CL}_{\text {int,hep,CYP }}$ and $\mathrm{CL}_{\text {int,mic,CYP }}$ ) was corrected for unspecific binding $\left(\mathrm{CL}_{\text {int,u,hep }}\right.$ and $\mathrm{CL}_{\mathrm{int}, \mathrm{u}, \mathrm{mic}}$ or $\mathrm{CL}_{\mathrm{int}, \mathrm{u}, \mathrm{hep}, \mathrm{CYP}}$ and $\mathrm{CL}_{\text {int,u,mic,CYP }}$ ) by dividing $\mathrm{CL}_{\text {int }}$ with $f_{\mathrm{u} \text {,hep }}$ or $f_{\mathrm{u} \text {,mic }}$, respectively, as previously described.

Intracellular and Microsomal Compound Binding. Compound binding to the cell homogenate or microsomal fraction was determined using dialysis in the cassette mode, as previously described. ${ }^{21}$ Briefly, the cell homogenate or microsome fraction was spiked with the compounds and dialyzed for $4 \mathrm{~h}$ at $37{ }^{\circ} \mathrm{C}$ using a Rapid Equilibrium Dialysis device (Thermo Fisher Scientific Inc.). Protein was precipitated with acetonitrile/water (60:40) spiked with $50 \mathrm{nM}$ warfarin, and samples were analyzed using UPLC-MS/MS, as described below. The fraction of unbound compound in the cell homogenate $\left(f_{\mathrm{u}, \text { hom }}\right)$ or microsomal fraction $\left(f_{\mathrm{u}, \mathrm{mic}}\right)$ was calculated, as previously described ${ }^{21}$

$$
f_{\mathrm{u}, \text { hom }} \text { or } f_{\mathrm{u}, \mathrm{mic}}=\frac{\mathrm{PA}_{\text {buffer }}}{\mathrm{PA}_{\text {hom }} \text { or } \mathrm{PA}_{\text {mic }}}
$$

where $\mathrm{PA}_{\text {buffer }}$ is the peak area of compound in the buffer chamber and $\mathrm{PA}_{\text {hom }}$ or $\mathrm{PA}_{\text {mic }}$ is the peak area of compound in the homogenate or microsomal chamber, respectively, all corrected for the peak area of the internal standard. The fraction of unbound compound in hepatocytes $\left(f_{\mathrm{u}, \text { cell }}\right)$ was calculated according to

$$
f_{\mathrm{u}, \text { cell }}=\frac{1}{D \times\left(1 / f_{\mathrm{u}, \text { hom }}-1\right)+1}
$$

where $D$ was estimated for each homogenate preparation based on a cellular volume of $6.5 \mu \mathrm{L} / \mathrm{mg}$ protein, ${ }^{34}$ and on the protein concentration measured using the BCA protein assay reagent kit. The $f_{\mathrm{u} \text {,hep }}$ used for $\mathrm{CL}_{\text {int,u,hep }}$ was calculated as $f_{\mathrm{u}, \text { cell }}$ but with $D$ being 0.1 corresponding to 10 times higher cell concentration in the binding experiment $\left(10 \times 10^{6}\right.$ hepatocytes $/ \mathrm{mL}$ ) than that in the intrinsic clearance measurement.

Intracellular Compound Accumulation. The compound accumulation in $\mathrm{HH}$ was determined after 15 and $30 \mathrm{~min}$ incubations. Since the accumulation was near-identical for both time points, their average value was used for all compounds, except diclofenac. For diclofenac, only the $15 \mathrm{~min}$ time point was used due to its rapid metabolism. An aliquot was collected at each time point, and cells were separated from the medium by 5 min centrifugation at $100 \mathrm{~g}$ at $4{ }^{\circ} \mathrm{C}$. Medium was collected, and cells were washed once with ice-cold PBS and collected after 5 min centrifugation at $100 \mathrm{~g}$ at $4{ }^{\circ} \mathrm{C}$. Compounds were released from medium and cells into acetonitrile/water (60:40) spiked with $50 \mathrm{nM}$ warfarin and analyzed using UPLC-MS/MS, as described below. The ratio between the compound concentrations in the cells and medium (Kp) was calculated, as previously described ${ }^{21}$

$$
\mathrm{Kp}=\frac{A_{\text {cell }} /\left(V_{\text {cell }} \times P_{\text {cell }}\right)}{C_{\text {medium }}}
$$

where $A_{\text {cell }}$ is the amount of compound in the cell samples, $V_{\text {cell }}$ is the cellular volume (calculated based on the constant 6.5 $\mu \mathrm{L} / \mathrm{mg}$ protein $^{34}$ and the protein amount in the hepatocytes for each experiment), and $C_{\text {medium }}$ is the compound concentration in the medium.

Intracellular Unbound Drug Concentration. The intracellular unbound drug concentration in $\mathrm{HH}$ was calculated from the intracellular drug accumulation (Kp) and fraction unbound in the cell $\left(f_{\mathrm{u}, \text { cell }}\right)$ by

$$
\mathrm{Kp}_{\mathrm{uu}}=f_{\mathrm{u}, \text { cell }} \times \mathrm{Kp}
$$

Compound Quantification. Samples were centrifuged for $20 \mathrm{~min}$ at $2465 \mathrm{~g}$ at $4{ }^{\circ} \mathrm{C}$, and the compounds in the supernatant were analyzed by UPLC-MS/MS, consisting of a Waters Xevo TQMS with electrospray ionization coupled to a Waters Acquity UPLC. Compounds were separated with a 1.8 min gradient elution of acetonitrile and $0.1 \%$ formic acid (flow rate $0.5 \mathrm{~mL} / \mathrm{min}$ ) on a Waters BEH C18 column, $2.1 \times 50 \mathrm{~mm}$ $(1.7 \mu \mathrm{m})$ at $60{ }^{\circ} \mathrm{C}$ (see Table S2 for LC-MS/MS conditions).

Scaling $\mathrm{CL}_{\text {int,u }}$ to In Vivo $\mathrm{CL}_{\text {int,mic }}$ and $\mathrm{CL}_{\text {int,hep }}(\mathrm{mL} / \mathrm{min} /$ kg Body Weight). To investigate factors that could influence the $\mathrm{CL}_{\text {int }}$ calculated for $\mathrm{HH}$ and HLM, three different ways of scaling the in vitro clearance to $\mathrm{mL} / \mathrm{min} / \mathrm{kg}$ body weight $(\mathrm{mL} /$ $\mathrm{min} / \mathrm{kg} \mathrm{bw}$ ) were tested. 


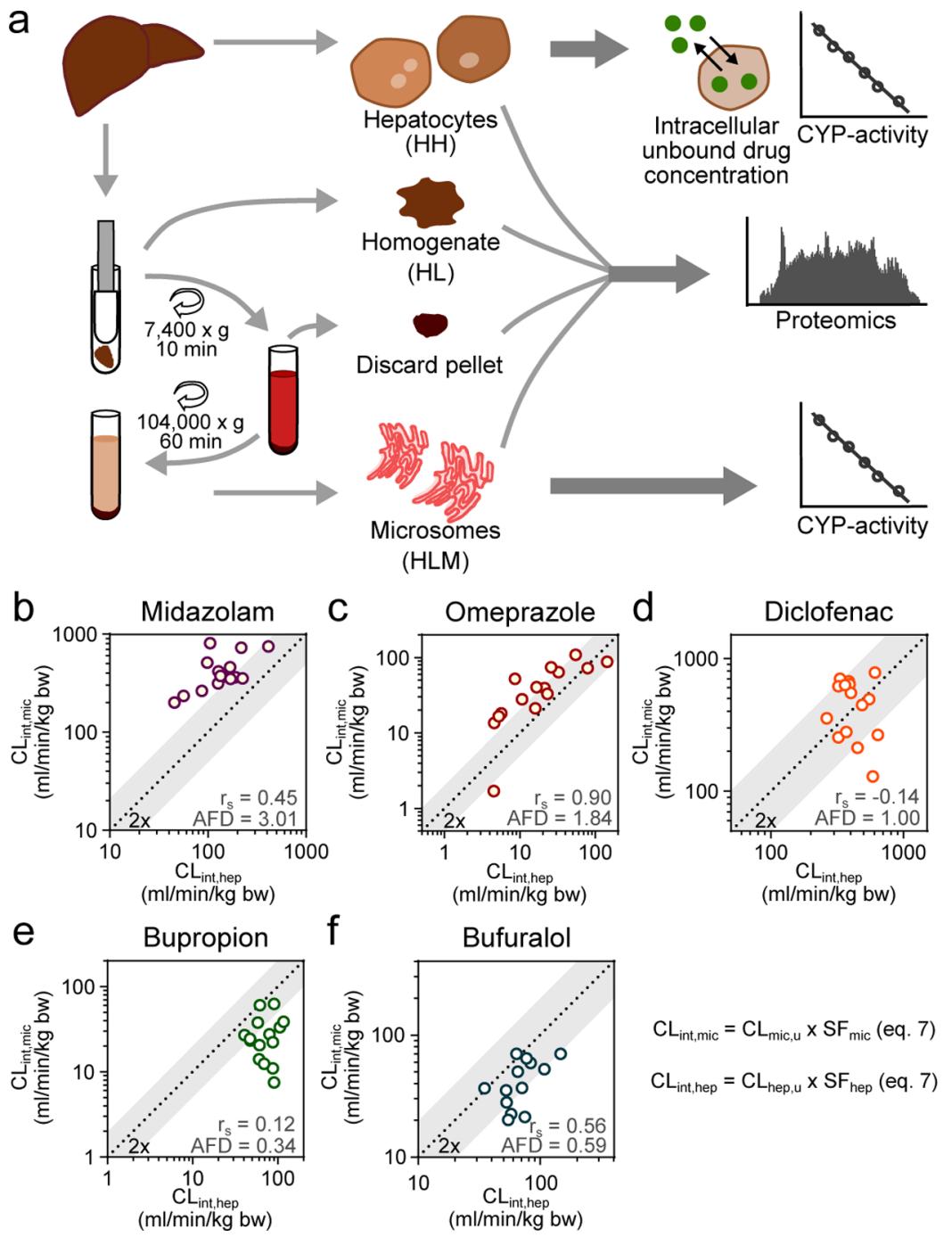

Figure 1. Metabolic activity of drug metabolizing enzymes in human liver microsomes (HLM) and hepatocytes (HH). (a) Workflow of the collection of the different sample types (HH, HL, discard pellets, and HLM), and which experiments were conducted using the respective sample type. (b-f) Intrinsic clearance of five probe CYP substrates (midazolam, omeprazole, diclofenac, bupropion, and bufuralol) measured in 15 donormatched HLM and HH. Unbound in vitro clearance was scaled to kg body weight with eq 7. $r_{\mathrm{s}}=$ Spearman's rank correlation coefficient and AFD $=$ average fold difference (eq 10). ${ }^{36}$

(1) $\mathrm{CL}_{\text {int,u }}$ values from $\mathrm{HH}$ and HLM (eq $1, \mathrm{~mL} / \mathrm{min} / \mathrm{mg}$ protein) were scaled to $\mathrm{mL} / \mathrm{min} / \mathrm{kg}$ bw with literature scaling factors:

$$
\begin{aligned}
\mathrm{CL}_{\text {int,mic }} & =\mathrm{CL}_{\text {int,u,mic [eq 1] }} \times \mathrm{SF}_{\text {mic }} \text { or } \mathrm{CL}_{\text {int,hep }} \\
& =\mathrm{CL}_{\text {int,u,hep [eq 1] }} \times \mathrm{SF}_{\text {hep }}
\end{aligned}
$$

w h e r e

$\mathrm{SF}_{\text {mic }}=45 \mathrm{mg}$ microsomal protein $/ \mathrm{g}$ liver $\times \frac{1500 \mathrm{~g} \text { liver }}{70 \mathrm{~kg} \text { body weight }}$

$2,4,5,7,35$

$\mathrm{SF}_{\text {hep }}=$ hepatocellularity of $120 \times 10^{6}$ cells $/ \mathrm{g}$ liver. ${ }^{1,2,5,7}$

$$
\times \frac{1500 \mathrm{~g} \text { liver }}{70 \mathrm{~kg} \text { body weight }}
$$

(2) $\mathrm{CL}_{\text {int,u }}$ values from $\mathrm{HH}$ and HLM normalized against the specific probed CYP (eq 2, $\mathrm{mL} / \mathrm{min} / \mathrm{pmol}$ CYP) were scaled to $\mathrm{mL} / \mathrm{min} / \mathrm{kg}$ bw using the amount of the corresponding CYP in the liver:

$$
\begin{aligned}
\mathrm{CL}_{\text {int, mic,CYP }}= & \mathrm{CL}_{\text {int, u, mic, CYP [eq 2] }} \times \text { Hom }_{\mathrm{CYP}} \times \text { HomPGL } \\
& \times \frac{1500 \text { g liver }}{70 \mathrm{~kg} \text { body weight }} \\
\text { or } & \mathrm{CL}_{\text {int,hep,CYP }} \\
& \times \frac{1500 \text { g liver }}{70 \mathrm{~kg} \text { body weight }}
\end{aligned}
$$

where $\mathrm{CL}_{\text {int,u,mic,CYP }}$ and $\mathrm{CL}_{\text {int,u,hep,CYP }}$ are the clearance measured in HLM and $\mathrm{HH}$, respectively, per amount of specific probe CYP protein $(\mathrm{mL} / \mathrm{min} / \mathrm{pmol}$ CYP $)$. Hom $_{\mathrm{CYP}}$ is the specific probe CYP concentration in $\mathrm{HL}$ ( $\mathrm{pmol} \mathrm{CYP} / \mathrm{mg}$ total protein) determined, as described under the "Protein Quantification" section, and HomPGL is the mg total protein in the liver homogenate per gram liver tissue (92 mg total protein/g liver determined from the 15 donors from the "Subcellular Fractionation and Microsomal Preparation" section). 


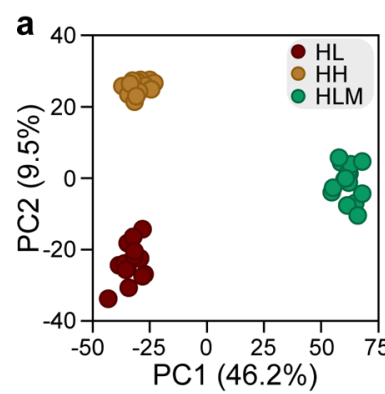

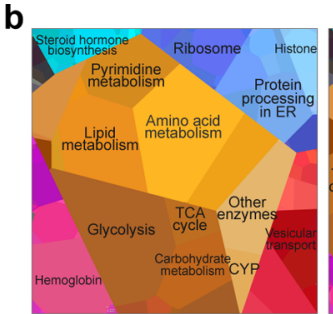

$\mathrm{HL}$

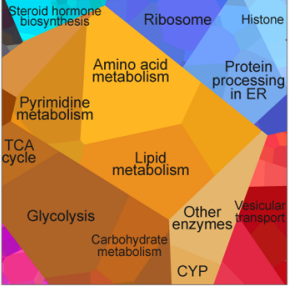

$\mathrm{HH}$

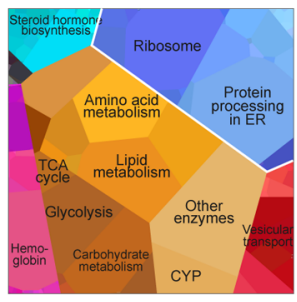

HLM
C
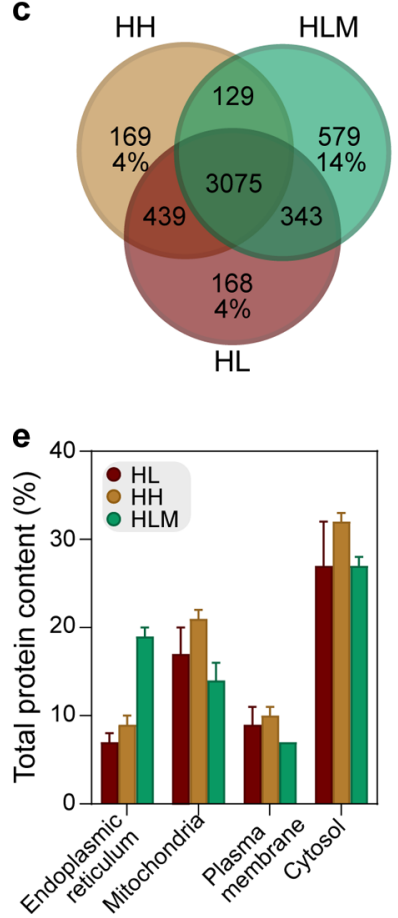

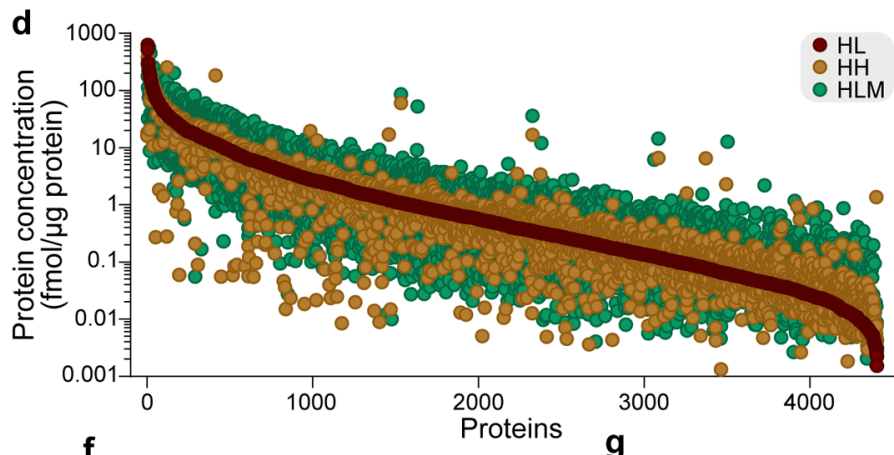

f
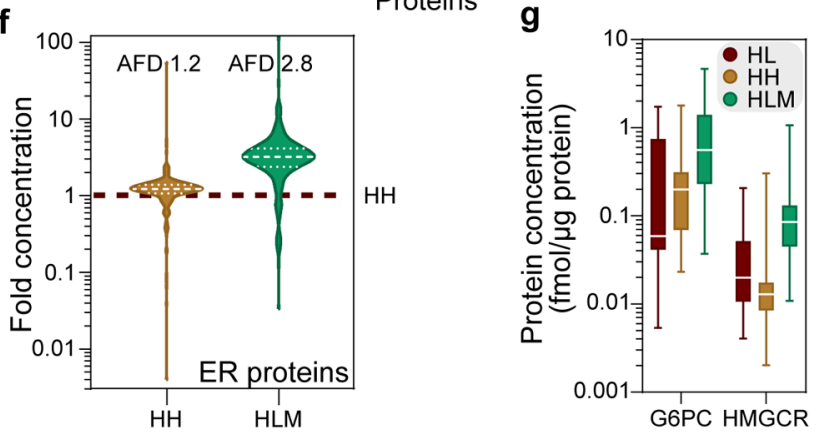

Figure 2. Global proteomics analysis of human liver (HL) homogenates, isolated hepatocytes $(\mathrm{HH})$, and liver microsomes (HLM). (a) PCA of proteins in HL, HH, and HLM from 15 donors. (b) Proteomaps ${ }^{39}$ displaying the quantitative composition of protein function in the proteomes of the three sample types, using average concentrations from the 15 donors. The size of each polygon indicates the abundance of proteins involved in the cellular function according to the KEGG pathway. (c) Overlap of quantified proteins in each sample type. (d) Range of concentrations of overlapping proteins in each sample type, based on average concentrations from the 15 donors. Proteins are ranked based on the median concentration in the HL. (e) Proportion of the total protein content in different subcellular locations (proteins annotated by HPA ${ }^{40}$ ). Bars show average levels, and error bars denote standard deviation for the 15 donors. (f) Distribution of fold concentrations of ER-located proteins in HH and HLM compared to HL. Dashed and dotted white lines denote median, and upper and lower quartiles, respectively. (g) Protein concentrations of historically used activity markers in HLM for ER in the three sample types. The lines shows median values and whiskers minimum and maximum values from the 15 donors. AFD, average fold difference. ${ }^{36}$

(3) The $\mathrm{CL}_{\text {int,mic,CYP }}$ was adjusted for the intracellular unbound concentrations $\left(\mathrm{Kp}_{\mathrm{uu}}\right)$ from $\mathrm{HH}$ by:

$$
\mathrm{CL}_{\text {int,mic, } \mathrm{CYP}, \mathrm{Kp}_{\mathrm{uu}}}=\mathrm{CL}_{\text {int, mic, } \mathrm{CYP}[\mathrm{eq} 8]} \times \mathrm{Kp}_{\mathrm{uu}}
$$

Statistical Analysis. Average fold difference (AFD) and absolute AFD (AAFD) were calculated by

$$
\begin{aligned}
& \text { AFD }=10^{\sum \log (\text { fold-difference }) / N} \\
& \text { AAFD }=10^{\sum \log (\text { fold-difference }) / / N}
\end{aligned}
$$

where the fold difference is the ratio between each comparison and $N$ denotes the number of comparisons carried out in the analysis. $^{36}$

Proteins that were identified with at least three peptides were considered for the bioinformatics analysis. Principal component analysis (PCA) was performed using SIMCA (Sartorius Stedim Biotech), version 15.0.0.4783. Enriched proteins were determined using $t$-test with a permutationbased FDR calculation (implemented in Perseus, ${ }^{37}$ version 1.6.2.3). Functional annotation clustering of GOBP, GOCC, and KEGG terms was performed with David, version 6.8, using default settings. ${ }^{38}$ Enriched protein functions were analyzed using Proteomaps. ${ }^{39}$ Proteins were annotated with subcellular locations from the "Subcellular location" data from the Human Protein Atlas (HPA), ${ }^{40}$ where proteins were classified in the following groups "ER," "plasma membrane," "mitochondria," "Golgi apparatus," “cytosol," and "nucleus" (including nucleoplasm, nuclear speckles, nuclear membrane, nuclear bodies, nucleoli, nucleoli fibrillary center, and nucleus). Proteins localized in several subcellular groups in the HPA were annotated to all of these subcellular compartments. Statistical analysis and figures were made using GraphPad Prism, version 7.03, and Excel. Pearson's correlation coefficients were calculated from logarithmic values. 


\section{a}

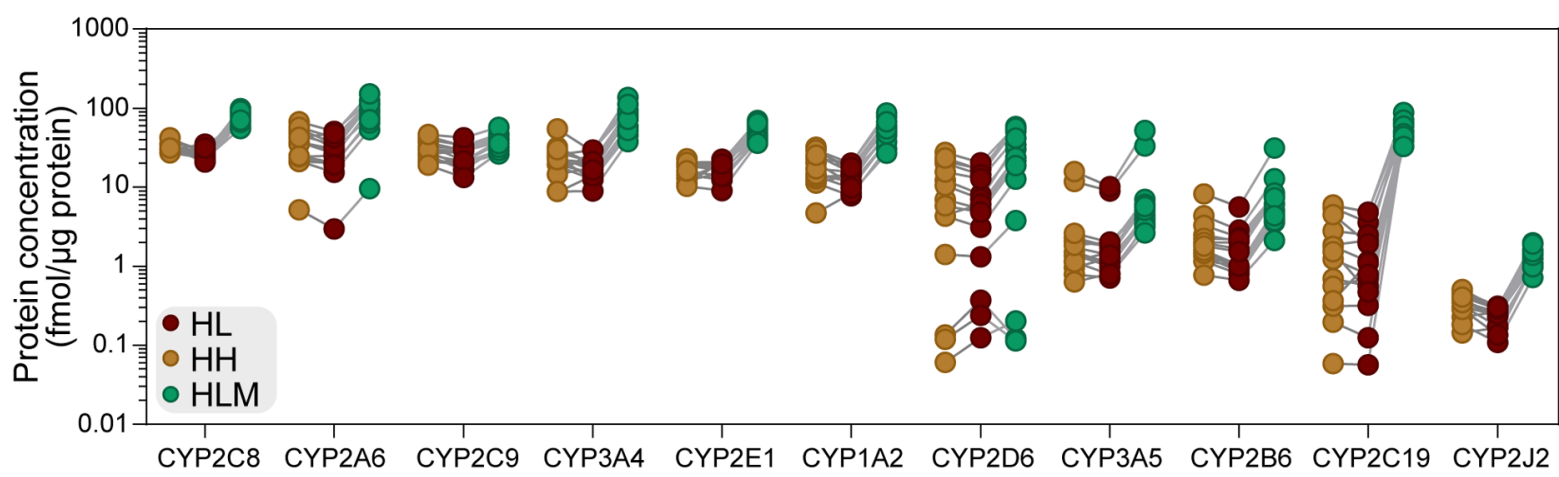

Spearman's rank correlation

\begin{tabular}{|c|c|c|c|c|c|c|c|c|c|c|c|}
\hline $\mathrm{HH}-\mathrm{HL}$ & 0.01 & 0.94 & 0.88 & 0.54 & 0.16 & 0.71 & 0.99 & 0.87 & 0.99 & 0.93 & 0.81 \\
\hline $\mathrm{HH}-\mathrm{HLM}$ & 0.38 & 0.87 & 0.79 & 0.48 & 0.44 & 0.68 & 0.97 & 0.83 & 0.93 & 0.66 & 0.76 \\
\hline$\underline{H L}-\mathrm{HLM}$ & 0.15 & 0.95 & 0.87 & 0.96 & 0.71 & 0.90 & 0.98 & 0.91 & 0.92 & 0.70 & 0.88 \\
\hline \multicolumn{12}{|c|}{ Average enrichment } \\
\hline HLM/HH & 2.3 & 2.6 & 1.2 & 3.5 & 3.2 & 3.1 & 2.5 & 3.3 & 3.2 & 46 & 3.9 \\
\hline$\underline{\mathrm{HLM} / \mathrm{HL}}$ & 2.9 & 3.2 & 1.5 & 4.1 & 3.0 & 3.8 & 2.6 & 3.8 & 4.2 & 56 & 5.5 \\
\hline
\end{tabular}

b $\circ \mathrm{HH}$

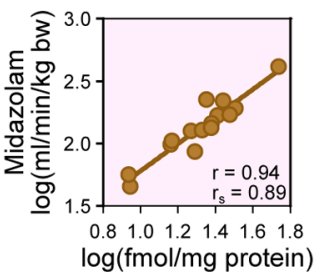

CYP3A4

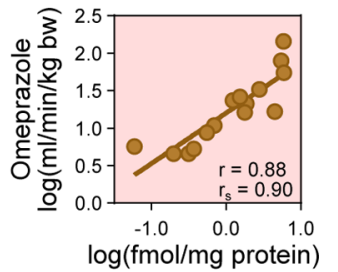

CYP2C19
C $\odot$ HLM

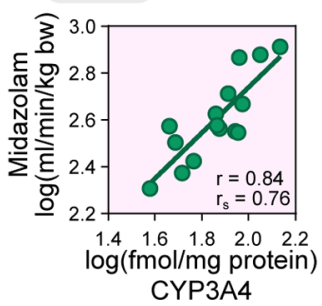

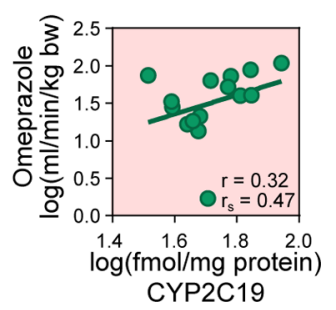

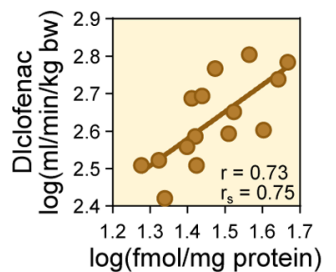

CYP2C9

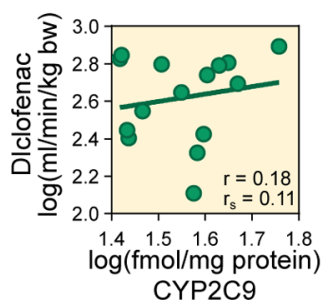

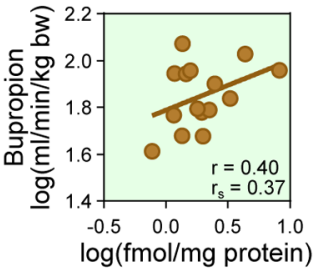

CYP2B6

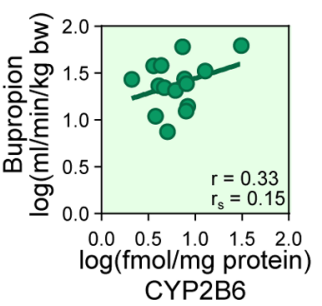

Spearman's correlation 0.7

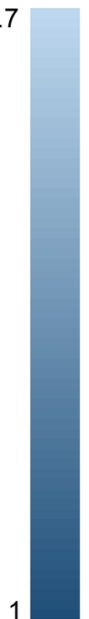

Figure 3. Protein concentration and metabolic activity of drug metabolizing enzymes. (a) Protein concentrations of CYP enzymes in liver homogenate (HL), isolated hepatocytes (HH), and liver microsomes (HLM) from the 15 donors. Concentration levels are given in fmol/ $\mu \mathrm{g}$ total protein. Spearman's rank correlations $\left(r_{\mathrm{s}}\right)$ compare the relative expression of each enzyme across the donors between the sample type, with significant correlation coefficients $>0.7$ ( $p<0.006$, after Bonferroni correction for multiple comparisons). Average enrichment of HLM compared to $\mathrm{HL}$ and $\mathrm{HH}$ was calculated based on concentrations from the 15 donors. $(\mathrm{b}, \mathrm{c})$ Comparison of metabolic activity $\left(\mathrm{CL}_{\text {int,hep }}\right.$ and $\mathrm{CL}_{\text {int,mic }}$ eq 7$)$ of the probe substrates and protein concentrations of the corresponding probe CYP enzymes in the donor-matched HH and HLM. $r=$ Pearson's correlation coefficient calculated from the log-transformed values and $r_{s}=$ Spearman's rank correlation coefficient.

\section{RESULTS}

Comparison of Metabolic Activity in HLM and HH from 15 Matched Donors. Most in vitro drug metabolism studies use HLM and HH derived from different and pooled donor batches. ${ }^{1,2,7}$ While this gives a good estimate of the drug clearance for the average population, it does not reflect interindividual differences. Also, direct comparisons of the systems are not possible. To address this limitation, the first step of our analysis was to investigate the influence of inter-individual variability on the differences in intrinsic clearance $\left(\mathrm{CL}_{\text {int }}\right)$ between the two systems. For this purpose, we produced HLM and $\mathrm{HH}$ from liver samples obtained from the same 15 human donors (Figure 1a) and analyzed the clearance of five probe CYP substrates (bupropion-CYP2B6, diclofenac-CYP2C9,
omeprazole-CYP2C19, bufuralol-CYP2D6, and midazolam-CYP3A4; Figure $1 b-f)$.

We noted a generally higher $\mathrm{CL}_{\text {int }}$ in HLM for midazolam $(\mathrm{AFD}=3.01)$ and omeprazole $(\mathrm{AFD}=1.84)$ across the 15 donors (calculated from eq 7). The median midazolam $\mathrm{CL}_{\text {int,mic }}$ was $375 \mathrm{~mL} / \mathrm{min} / \mathrm{kg}$ bodyweight (bw) (range 203$819 \mathrm{~mL} / \mathrm{min} / \mathrm{kg} \mathrm{bw}$ ) compared to the median $\mathrm{CL}_{\text {int,hep }}$ of 134 $\mathrm{mL} / \mathrm{min} / \mathrm{kg}$ bw $(45-414 \mathrm{~mL} / \mathrm{min} / \mathrm{kg}$ bw). The median omeprazole $\mathrm{CL}_{\text {int,mic }}$ was $40 \mathrm{~mL} / \mathrm{min} / \mathrm{kg}$ bw $(2-109 \mathrm{~mL} /$ $\mathrm{min} / \mathrm{kg} \mathrm{bw}$ ) compared to the median $\mathrm{CL}_{\text {int,hep }}$ of $17 \mathrm{~mL} / \mathrm{min} /$ $\mathrm{kg}$ bw (5-144 mL/min/kg bw; Figure 1b,c, Table S3; and Figures S6 and S7).

In contrast, the $\mathrm{CL}_{\text {int }}$ values of bupropion and bufuralol were generally higher in $\mathrm{HH}$ across the 15 donors $(\mathrm{AFD}=0.34$ and 0.63 , respectively), where the median bupropion $\mathrm{CL}_{\text {int,mic }}$ was 
$24 \mathrm{~mL} / \mathrm{min} / \mathrm{kg}$ bw $(8-62 \mathrm{~mL} / \mathrm{min} / \mathrm{kg} \mathrm{bw})$ compared to the median $\mathrm{CL}_{\text {int,hep }}$ of $69 \mathrm{~mL} / \mathrm{min} / \mathrm{kg}$ bw $(41-118 \mathrm{~mL} / \mathrm{min} / \mathrm{kg}$ bw). The median bufuralol $\mathrm{CL}_{\text {int,mic }}$ was $37 \mathrm{~mL} / \mathrm{min} / \mathrm{kg}$ bw (20-70 $\mathrm{mL} / \mathrm{min} / \mathrm{kg} \mathrm{bw}$ ) compared to median bufuralol $\mathrm{CL}_{\text {int,hep }}$ of $66 \mathrm{~mL} / \mathrm{min} / \mathrm{kg}$ bw $(22-146 \mathrm{~mL} / \mathrm{min} / \mathrm{kg}$ bw; Figure 1e,f, Table S3; and Figures S8 and S10).

The $\mathrm{CL}_{\text {int }}$ of diclofenac was in general similar in HLM and $\mathrm{HH}(\mathrm{AFD}=0.99)$, with median diclofenac $\mathrm{CL}_{\text {int,mic }}$ of 494 $\mathrm{mL} / \mathrm{min} / \mathrm{kg}$ bw $(129-782 \mathrm{~mL} / \mathrm{min} / \mathrm{kg} \mathrm{bw})$ compared to the median $\mathrm{CL}_{\text {int,hep }}$ of $392 \mathrm{~mL} / \mathrm{min} / \mathrm{kg}$ bw $(263-637 \mathrm{~mL} / \mathrm{min} / \mathrm{kg}$ bw; Figure 1d, Table S3; and Figure S9).

With these systematic differences in the $\mathrm{CL}_{\text {int }}$ of HLM and $\mathrm{HH}$ from matching donors, we ruled out inter-individual variability in drug metabolism of these probe substrates as the reason. We propose that the differences are rather an artifact of improper scaling.

Comparison of the Protein Profiles of $\mathrm{HLM}, \mathrm{HH}$, and $\mathrm{HL}$. In scaling in vitro clearance from HLM to $\mathrm{mL} / \mathrm{min} / \mathrm{kg}$ bw, a standard yield of $\mathrm{mg}$ microsomal protein per gram liver (MPPGL) is commonly used as a scaling factor (as used in eq 7)..$^{2,4,7}$ Although this commonly applied MPPGL is corrected for microsomal recovery of certain proteins (e.g., by accounting for activity measurements of microsomal markers ${ }^{4,42}$ ), the microsomal fraction contains all proteins obtained in the fraction collected during the subcellular processing. Therefore, microsomal recovery may not reflect differences in amounts of the actual proteins involved in the metabolic activity. To better understand the differences in protein composition in HLM, HH, and homogenate of HL, we used global proteomics analysis (Figure 1a). The complete data sets from the matched donors are available in the Supporting Information (Data S1). Both PCA and functional analysis of the proteomes using Proteomaps ${ }^{39}$ showed that the overall protein composition of HLM differed from both the $\mathrm{HH}$ and HL (Figure 2a; Figure 2b). Biosynthesis processes (amino acid metabolism, glycolysis, carbohydrate metabolism, and lipid metabolism) dominated in all three sample types, but the HLM Proteomap had the largest proportion of proteins related to the ER, where CYP enzymes are located (Figure $2 b$ ). Of 3989 proteins, 3075 (77\%) were the same for the three systems (Figure 2c). Despite this large overlap in the identity of the quantified proteins, the protein expression levels of HLM differed from both the HL (AAFDs of 3.0) and HH (AAFD 3.1; Figure 2d). HLM proteins had significantly higher concentrations (Figure S1a; FDR $=0.01$ and S0 $=2$ ) of proteins involved in ER-associated pathways, such as fatty acid and drug metabolism (Data S2). This is in line with that HLMs are considered to be vesicles derived from the ER. ${ }^{12}$

Since we found such a big overlap in proteins in HLM, HH, and $\mathrm{HL}$, we investigated the fractional contribution (\% total protein content) of proteins from different subcellular locations. ${ }^{40}$ This analysis confirmed that ER-annotated proteins made up a larger proportion of the total protein content in the HLM (19\%) than that in the HL (7\%) and $\mathrm{HH}$ (9\%; Figure 2e). However, the HLM also contained proteins associated with other subcellular compartments, including mitochondria (14\% of the total HLM protein content, compared to 17 and $21 \%$ in $\mathrm{HL}$ and $\mathrm{HH}$, respectively). The proportion of cytosolic proteins was comparable for HLM (27\%), HL (27\%), and HH (32\%). However, HLM also contained a large proportion of nuclear proteins (19\%) that are expected to be captured by the first low-speed centrifugation pellet $^{43-46}$ (the "discard pellet"; Figure 1a). In fact, the fraction of nuclear proteins in HLM was comparable to that in the discard pellets (which contained $20 \%$ nuclear proteins) and not much lower than either HL $(28 \%)$ or $\mathrm{HH}$ (24\%; Figure $\mathrm{S} 1 \mathrm{~b}-\mathrm{d})$. This demonstrates that the HLM fractions are "contaminated" with many proteins that are not associated with the ER compartment, an observation supported by previous investigations. ${ }^{18,19}$

We further investigated the enrichment of ER-annotated proteins. As with the complete set of quantified proteins, the HLM, HL, HH, and discard pellet all contained substantial concentrations of ER-associated proteins (Figure S1e-h). The ER-related proteins were enriched in general 2.8-fold (Figure $2 \mathrm{f}, \mathrm{g}$ ) in the HLM but with a large variability ranging from 0.03 to 120 -fold for the different proteins.

Enrichment of CYP Enzymes in HLM. The variability in enrichment for the supposedly ER-localized proteins in HLM made us suspect that the HLM preparation procedure itself might be responsible for the variability in CYP enzyme levels. This in turn would be reflected by variability in measurements of metabolic activity. The median concentrations of the most important drug metabolizing CYP enzymes ${ }^{47}$ in HLM ranged from 1.3 (CYP2J2) to 76.5 (CYP2C8) $\mathrm{fmol} / \mu \mathrm{g}$ protein (Figure 3a) for the 15 donors. Similar to the other ERannotated proteins, the average enrichment of CYP enzymes was 3.2-fold higher in the HLM than that in the HL and $\mathrm{HH}$ ( $\mathrm{HL}$ and $\mathrm{HH}$ CYP levels were in good agreement with previous reports; Figures $3 a$ and $S 2 b, c^{48-50}$ ). However, the CYP enzymes were enriched to different degrees in HLM than that in $\mathrm{HL}$ and $\mathrm{HH}$, ranging from 1.2 (CYP2C9) to 56 (CYP2C19)-fold. The rank order of donors was in general similar to the three sample types [median Spearman's rank correlation $\left(r_{\mathrm{s}}\right)$ of 0.87 ; Figure $3 \mathrm{a}$ and Table S3]. This indicates that the procedure for preparing HLM and $\mathrm{HH}$ samples preserved the order in the liver samples (i.e., donors with the highest specific CYP concentrations in HL also showed the highest concentrations in HLM and HH). For CYP3A4 and CYP2C19 (probed by midazolam and omeprazole, respectively), the rank correlations between protein concentrations in HLM and $\mathrm{HH}$ were weaker $\left(r_{\mathrm{s}}=\right.$ 0.48 and $r_{\mathrm{s}}=0.66$, respectively; Figure $3 \mathrm{a}$ and Table S3), which could potentially translate to differences in metabolic clearance.

Impact on Concurrence Between HLM and $\mathrm{HH} \mathrm{CL}_{\text {int }}$ from Normalization with the Amount of Specific CYP. To investigate whether variable enrichment of CYP enzymes contributed to the differences in $\mathrm{CL}_{\text {int }}$ from HLM and $\mathrm{HH}$, we normalized $\mathrm{CL}_{\text {int }}$ with the amounts of individual CYPs probed by each of the five substrates, instead of using total protein (HLM) or number of cells $(\mathrm{HH})$ (eq 8 ; giving $\mathrm{mL} / \mathrm{min} / \mathrm{pmol}$ CYP). This normalization for CYP3A4 resulted in more similar $\mathrm{CL}_{\text {int,CYP }}$ values for midazolam in HLM and $\mathrm{HH}$, with the AFD improving from 3.01 to 1.62 (Table 2; Table S3; and Figure S11).

However, for the other four compounds, normalization with the respective CYP probe (eq 8) resulted in larger differences in $\mathrm{CL}_{\text {int }}$ than normalization to $\mathrm{mg}$ protein or million hepatocytes (eq 7; Table 2; Table S3; and Figure S11). For diclofenac, AFD increased from 1.00 to 1.55. Meanwhile, AFDs were reduced for bupropion (from 0.34 to 0.2 ), omeprazole (from 1.84 to 0.08 ), and bufuralol (from 0.59 to $0.42)$. Notably, three outliers in the omeprazole correlation had surprisingly comparable unadjusted $\mathrm{CL}_{\text {int }}$ in $\mathrm{HLM}$ and $\mathrm{HH}$, despite 42-fold to 228-fold higher CYP2C19 levels in 
Table 2. AFD and Correlation Parameters from Comparisons of $\mathrm{CL}_{\mathrm{int} \text {,mic }}$ and $\mathrm{CL}_{\text {int,hep }}$ Calculated with Different Scaling Factors ${ }^{a}$

\begin{tabular}{|c|c|c|c|c|}
\hline & & $\begin{array}{c}\text { literature } \\
\text { scaling } \\
\text { factors (eq 7) }\end{array}$ & $\begin{array}{l}\text { proteomics } \\
\text { scaling factors } \\
\quad(\text { eq } 8)\end{array}$ & $\begin{array}{l}\text { proteomics and } \\
\mathrm{Kp}_{\mathrm{uu}} \text { scaling } \\
\text { factors (eq 9) }\end{array}$ \\
\hline \multirow[t]{3}{*}{ midazolam } & AFD & 3.01 & 1.62 & 0.52 \\
\hline & $r_{\mathrm{s}}$ & 0.45 & 0.66 & 0.66 \\
\hline & $r$ & 0.64 & 0.78 & 0.82 \\
\hline \multirow[t]{3}{*}{ omeprazole } & AFD & 1.84 & 0.08 & 0.12 \\
\hline & $r_{\mathrm{s}}$ & 0.90 & 0.92 & 0.90 \\
\hline & $r$ & 0.77 & 0.87 & 0.87 \\
\hline \multirow[t]{3}{*}{ diclofenac } & AFD & 1.00 & 1.55 & 1.11 \\
\hline & $r_{\mathrm{s}}$ & -0.14 & 0.28 & 0.41 \\
\hline & $r$ & -0.22 & 0.21 & 0.39 \\
\hline \multirow[t]{3}{*}{ bupropion } & AFD & 0.34 & 0.20 & 0.24 \\
\hline & $r_{\mathrm{s}}$ & 0.12 & 0.08 & -0.03 \\
\hline & $r$ & 0.00 & 0.01 & -0.01 \\
\hline \multirow[t]{3}{*}{ bufuralol } & AFD & 0.59 & 0.42 & 1.08 \\
\hline & $r_{\mathrm{s}}$ & 0.56 & 0.68 & 0.62 \\
\hline & $r$ & 0.52 & 0.73 & 0.67 \\
\hline
\end{tabular}

$a_{r}=$ Pearson's correlation coefficient calculated from log-transformed values, $r_{\mathrm{s}}=$ Spearman's rank correlation coefficient, and AFD = average fold difference.

HLM. In contrast, bufuralol $\mathrm{CL}_{\text {int }}$ could not be determined in the HLM preparations of two donors due to undetectable depletion; meanwhile, relatively high $\mathrm{CL}_{\text {int }}(26$ and $170 \mathrm{~mL} /$ $\mathrm{min} / \mathrm{kg} \mathrm{bw}$; eq 8) was obtained in the corresponding $\mathrm{HH}$. These findings suggest that metabolic pathways other than the probed CYP enzymes contribute to the $\mathrm{CL}_{\text {int }}$ of omeprazole and bufuralol in the $\mathrm{HH}$.

In contrast to the mostly increased overall $\mathrm{CL}_{\text {int }}$ differences between HLM and HH in absolute values (AFD), the rank order agreement for the 15 donors improved for three of the compounds by compensating for specific CYP content: midazolam ( $r_{\mathrm{s}}$ from 0.45 to 0.66 ), diclofenac ( $r_{\mathrm{s}}$ from -0.14 to 0.28 ), and bufuralol ( $r_{\mathrm{s}}$ from 0.56 to 0.68 ). The rank order was unaffected though for omeprazole ( $r_{\mathrm{s}}$ from 0.90 to 0.92 ) and bupropion ( $r_{\mathrm{s}}$ from 0.12 to 0.08 ). Accordingly, the explained variance (Pearson $r^{2}$ ) improved by taking CYP content into account. Thus, compensating for CYP amounts tended to cancel out some of the variability of the two experimental systems, while simultaneously introducing an offset in the $\mathrm{CL}_{\text {int }}$ values.

But why did the compensation for CYP amount not consistently improve the correspondence in absolute values (AFD) for HLM- and $\mathrm{HH}$-derived $\mathrm{CL}_{\text {int }}$ ? We further examined the correlations between $\mathrm{CL}_{\text {int }}$ and the CYP concentrations for each of the five probe substrates. For midazolam, $C_{\text {int }}$ $\left(\mathrm{CL}_{\text {int,mic }}\right.$ and $\mathrm{CL}_{\text {int,hep }}$ per mg protein and million hepatocytes; eq 7) correlated well with the CYP3A4 concentration in both HLM [Pearson's correlation coefficient $(r)=0.84)$ and HH $(r$ $=0.94$; Figure $3 \mathrm{~b}, \mathrm{c}]$. A high correlation was also found in $\mathrm{HH}$ between both omeprazole $\mathrm{CL}_{\text {int,hep }}$ and $\mathrm{CYP} 2 \mathrm{C} 19_{\mathrm{HH}}$ concentrations $(r=0.88)$ and diclofenac $\mathrm{CL}_{\text {int,hep }}$ and $\mathrm{CYP} 2 \mathrm{C} 9_{\mathrm{HH}}$ concentrations $(r=0.73)$. Correlations were lower in HLM for both probe substrates (omeprazole $\mathrm{CL}_{\text {int,mic }}-\mathrm{CYP} 2 \mathrm{C} 19_{\mathrm{HLM}} r$ $=0.32$; diclofenac $\mathrm{CL}_{\text {int,mic }}-\mathrm{CYP} 2 \mathrm{C} 9_{\mathrm{HLM}}, r=0.18$; Figure $3 \mathrm{~b}, \mathrm{c})$. (Notably, the correlations for omeprazole $\mathrm{CL}_{\text {int,mic }}-$ CYP2C19 ${ }_{\text {HLM }}$ were strongly influenced by one outlier, which was also an outlier in the HLM and HH correlation of CYP adjusted $\mathrm{CL}_{\text {int }}$. Without this outlier, the correlation improved to $r=0.49$ ). Interestingly, these two enzymes-both belonging to the subfamily CYP2C-were very differently enriched in the HLM. CYP2C9, with higher HL concentrations, was poorly enriched (AFD 1.4-fold) in the HLM, while CYP2C19, with lower HL concentrations, was 50-fold more concentrated in the HLM than that in either HL (56-fold) or HH (46-fold; Figure 3a; Table S3). In line with this, global analysis of the proteomics data showed that the proteins with higher initial HL concentrations were less enriched in the HLM $\left(r_{\mathrm{s}}=-0.33\right.$; Figure S3e).

For bupropion, lower correlations between $\mathrm{CL}_{\text {int }}$ and CYP2B6 concentration were obtained in both HLM and $\mathrm{HH}$ $\left(\mathrm{CL}_{\text {int,mic }}-\mathrm{CYP} 2 \mathrm{~B} 6_{\mathrm{HLM}}, r=0.33 ; \mathrm{CL}_{\text {int,hep }}-\mathrm{CYP} 2 \mathrm{~B} 6_{\mathrm{HH}}, r=\right.$ 0.40 ; Figure $3 \mathrm{~b}, \mathrm{c})$. Low correlations were also observed between bufuralol $\mathrm{CL}_{\text {int }}$ and CYP2D6 concentrations in both systems $\left(\mathrm{CL}_{\text {int,mic }}-\mathrm{CYP} 2 \mathrm{D} 66_{\mathrm{HLM}}, \quad r=0.14 ; \mathrm{CL}_{\text {int,hep }}-\right.$ CYP2D6 ${ }_{\mathrm{HH}}, r=0.13$; Figure 3b,c; Table 2; Table S3; and Figure S11). Notably, two donors had high bufuralol $\mathrm{CL}_{\text {int }}$ in both HLM and HH despite low CYP2D6 amounts, which further indicates that bufuralol is metabolized by enzymes other than CYP2D6 in the two systems.

Interestingly, the $\mathrm{CL}_{\text {int }}$ of the compounds also correlated well with levels of CYPs other than the ones they were probing. For instance, midazolam $\mathrm{CL}_{\text {int }}$ correlated well with the probed CYP3A enzymes, that is, CYP3A4 and CYP3A5, but it also correlated well with CYP1A2 levels in both HLM and HH. Similarly, omeprazole $\mathrm{CL}_{\text {int }}$ correlated well with the probed CYP2C19 in both HLM and HH. In addition, it also correlated well with CYP3A4, which metabolizes omeprazole to some extent, ${ }^{51}$ and with CYP1A2 levels (Figure S4a,b; Table S4) in both systems. This implies that several enzymes may be involved in the metabolism of these compounds and affect $\mathrm{CL}_{\text {int }}$ in both experimental systems.

Impact on Concurrence between $\mathrm{HLM}$ and $\mathrm{HH} \mathrm{CL}_{\text {int }}$ from Normalization by CYP Amount and Intracellular Unbound Drug Concentration $\left(\mathrm{Kp}_{\mathrm{uu}}\right)$. The amounts of probe-specific CYPs improved correlations but introduced a general shift in the $\mathrm{CL}_{\text {int }}$ values (i.e., increased $\mathrm{AFD}$ ). We therefore investigated whether accounting for intracellular unbound drug concentrations (as measured by $\mathrm{Kp}_{\mathrm{uu}}$ ) would correct these shifts. For this purpose, we determined $\mathrm{Kp}_{\mathrm{uu}}$ for each of the five compounds in $\mathrm{HH}$ from the 15 donors. For omeprazole, bupropion, and diclofenac, $\mathrm{Kp}_{\mathrm{uu}}$ varied close to 1 (median $\mathrm{Kp}_{\mathrm{uu}}=1.4,1.2$, and 0.7, respectively; Table 3; Figure 4; Table S3; and Figure S5b-d), indicating on average equal drug concentrations within and outside of the cell. $\mathrm{Kp}_{\mathrm{uu}}$ was lower for midazolam (median $\mathrm{Kp}_{\mathrm{uu}}=0.3$, range $0.2-0.7$, Table 3; Figure 4; Table S3; and Figure S5a), indicating that unbound drug concentrations were lower inside than outside

Table 3. Intracellular Unbound Concentration of Drugs in Human Hepatocytes

\begin{tabular}{|c|c|c|c|}
\hline & \multicolumn{2}{|r|}{$\mathrm{Kp}_{\mathrm{uu}}$} & $f_{\mathrm{u}, \text { cell }}$ \\
\hline & median & range $(\min \text { to } \max )^{a}$ & median \\
\hline midazolam & 0.31 & $0.14-0.66$ & 0.51 \\
\hline omeprazole & 1.43 & $0.7-2.61$ & 0.93 \\
\hline diclofenac ${ }^{b}$ & 0.73 & $0.31-2.07$ & 0.83 \\
\hline bupropion & 1.24 & $0.46-2.95$ & 0.96 \\
\hline bufuralol & 2.76 & $0.8-7.28$ & 0.76 \\
\hline
\end{tabular}

${ }^{a}$ Range across hepatocytes from 15 donors. ${ }^{b}$ Determined after 15 min incubation only. 


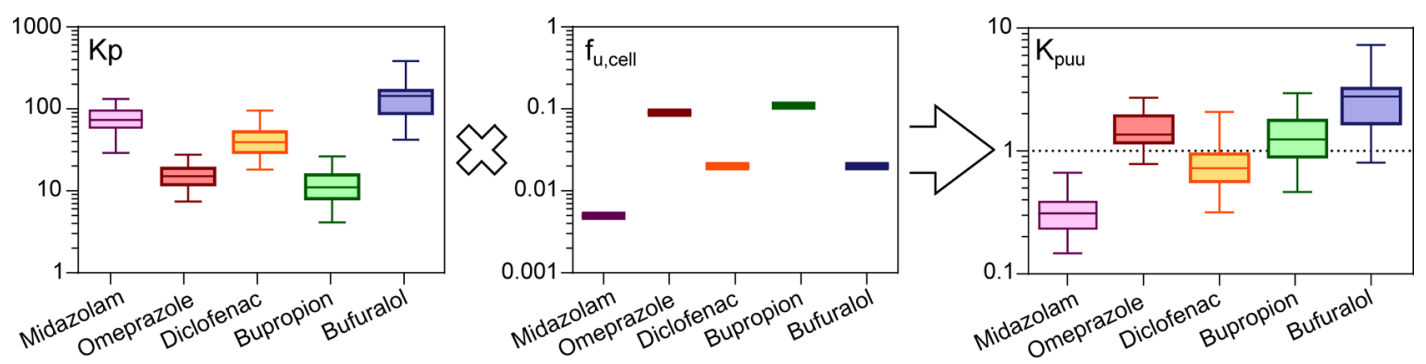

Figure 4. Intracellular unbound concentration of drugs in HHs. Accumulation $(\mathrm{Kp})$, unbound fraction $\left(f_{\mathrm{u}, \mathrm{cell}}\right)$, and intracellular unbound drug accumulation $\left(\mathrm{Kp}_{\mathrm{uu}}\right)$ of probe CYP substrates in $\mathrm{HH}$ from 15 donors.

of the cells. In contrast, bufuralol concentrations were slightly elevated intracellularly (median $\mathrm{Kp}_{\mathrm{uu}}=2.8$, range $0.8-7.3$, Table 3; Figure 4; Table S3; and Figure S5e), indicating an accumulation of unbound drug in the cell.

The $\mathrm{Kp}_{\mathrm{uu}}$ from each of the 15 donors was then used to adjust the respective CYP normalized $\mathrm{CL}_{\text {int }}$ in HLM $\left(\mathrm{CL}_{\text {int,mic,CYP,Kpuu; }}\right.$ eq 9). This resulted in overall improvements in the correspondence between HLM- and $\mathrm{HH}$-derived $\mathrm{CL}_{\text {int }}$ for four of the five compounds, although in some cases, the changes were minor (Figure 5a-j; Table 2; and Table S3).

$\mathrm{Kp}_{\mathrm{uu}}$-adjustment improved the AFD from 0.42 to 1.08 for bufuralol $\left(\mathrm{Kp}_{\mathrm{uu}}>1\right.$; Figure 5e,j; Table 2; and Table S3) and from 1.55 to 1.11 for diclofenac $\left(\mathrm{Kp}_{\mathrm{uu}}<1\right.$; Figure $5 \mathrm{c}$, h; Table 2; and Table S3). In contrast, the higher CYP-adjusted midazolam in HLM was over-compensated by the low intracellular unbound concentrations (median $\mathrm{Kp}_{\mathrm{uu}}$ of 0.3 ), which reduced AFD from 1.62 to 0.52 (Figure 5a,f and Table 2 ). Since midazolam is one of the more rapidly metabolized compounds, $\mathrm{Kp}_{\mathrm{uu}}$ may not accurately capture the constantly decreasing intracellular concentrations.

For bupropion and omeprazole, the near-unity $\mathrm{Kp}_{\mathrm{uu}}$ suggested that predictions would not be greatly affected. Both compounds retained similar AFDs as before and after $\mathrm{Kp}_{\mathrm{uu}}$ compensation (AFD improved marginally from 0.20 to 0.24 for bupropion and from 0.08 to 0.12 for omeprazole; Figure 5b,d,g,i; Table 2; and Table S3).

\section{DISCUSSION}

In this study, we sought to understand differences in metabolic activity obtained from the two major assay systems for drug metabolism studies, HLM and HH. To this end, we extensively investigated HLM and $\mathrm{HH}$ prepared from 15 matched donors. Specifically, we determined the metabolic $\mathrm{CL}_{\text {int }}$ of probe substrates of different CYP isoforms: CYP2B6 (bupropion), CYP2D6 (bufuralol), CYP2C9 (diclofenac), CYP2C19 (omeprazole), CYP3A4 (midazolam), and investigated factors that could influence the $\mathrm{CL}_{\text {int }}$, such as (1) inter-individual differences, (2) CYP amount, and (3) intracellular unbound drug concentrations $\left(\mathrm{Kp}_{\mathrm{uu}}\right)$. Furthermore, we quantified the global proteomes of HLM, HH, and the corresponding homogenated HL from the 15 matched donors. To the best of our knowledge, this is the first such donor-matched study.

Influence of Inter-individual Variability on Drug Metabolic $\mathrm{CL}_{\text {int }}$. We could rule out that the disconnect typically observed between $\mathrm{CL}_{\text {int }}$ in HLM and $\mathrm{HH}$ in the literature $^{1,2,7,13}$ is solely a result of inter-individual differences as our donor-matched samples still resulted in systematic differences in $\mathrm{CL}_{\text {int }}$ (AFD ranging from 0.34 to 2.95; Figure $1 \mathrm{a}-\mathrm{e}$, Table 2). This is in line with previous observations from a smaller-scale study. ${ }^{52}$ The fact that $\mathrm{CL}_{\text {int,mic }}$ was higher than
$\mathrm{CL}_{\text {int,hep }}$ for midazolam (CYP3A4) and omeprazole (CYP2C19) was in agreement with previous observations. ${ }^{2,7,13,53,54}$ For diclofenac-where we obtained similar $\mathrm{CL}_{\text {int }}$ in HLM and $\mathrm{HH}$-contradicting results have been reported previously, with $\mathrm{CL}_{\text {int }}$ either higher in $\mathrm{HLM}^{7,54}$ or in $\mathrm{HH}^{2,5}$ The higher $\mathrm{CL}_{\text {int,hep }}$ of bufuralol was in line with that shown previously.

The accuracy and appropriateness of the frequently used scaling factors for microsomes and hepatocytes (45 mg MPPGL and $120 \times 10^{6}$ cells/g liver, respectively), ${ }^{2,4,7,35,53}$ that we used in our initial comparison of $\mathrm{CL}_{\text {int }}$ from the two systems (eq 7), have been extensively discussed. ${ }^{3,56-58}$ It has been suggested that individual scaling factors determined for each batch may improve $\mathrm{CL}_{\text {int }}$ predictions in HLM and $\mathrm{HH} .{ }^{3,41,56-58}$ However, such scaling factors would still only consider the total activity in the two systems and not necessarily reflect differences in metabolic activity of specific enzymes. For instance, AFD in our study ranged from just below to just above unity for all five compounds [mean AFD between 0.34 (bupropion) and 2.96 (midazolam)]. Thus, selecting any common scaling factor would improve the predictions for some compounds while making others worse since changes to the scaling factor would move all data points in the same direction. This is in agreement with a previous observation where one scaling factor-calculated from the regression offset approach-was not sufficient for accurate in vitro-in vivo extrapolation of compounds with different metabolic profiles. ${ }^{13}$

Furthermore, although adjustments of the MPPGL scaling factor have been introduced to account for variable recovery of metabolic activity in the HLM preparations-for example using glucose-6-phosphatase activity or amount of total CYP enzymes as proxies ${ }^{41,42}$ - this is still only a general measure of the HLM activity. Thus, its validity is based on the assumption that all microsomal proteins are recovered to the same extent as the activity markers, and any differences in the recovery of specific proteins are not taken into account.

Global Proteomics Analysis of HLM, HH, and HL. Our global proteomics analysis confirmed that the $\mathrm{HH}$ samples had protein expression patterns similar to the ones of the HL samples from which they were isolated. This is as expected because $\mathrm{HH}$ is the dominating cell population in the liver, comprising approximately $80 \%$ of the liver volume. ${ }^{59}$ Furthermore, it indicates that the hepatocyte isolation procedure does not have a major effect on the $\mathrm{HH}$ proteome. In contrast, the HLM proteomes differed significantly from those of the corresponding HL and HH samples. HLM are considered as ER-derived vesicles ${ }^{12}$ and would therefore be expected to be enriched with ER-related proteins. However, the enrichment was lower than expected in HLM (on average 


\section{Scaling with literature MPPGL}

Eq. 7

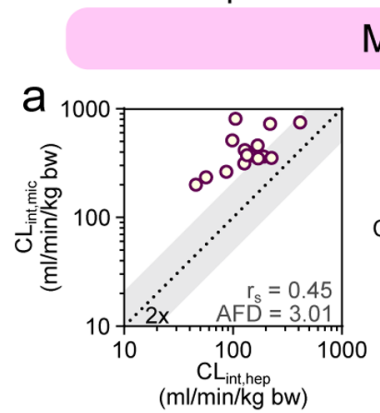

\section{Midazolam}
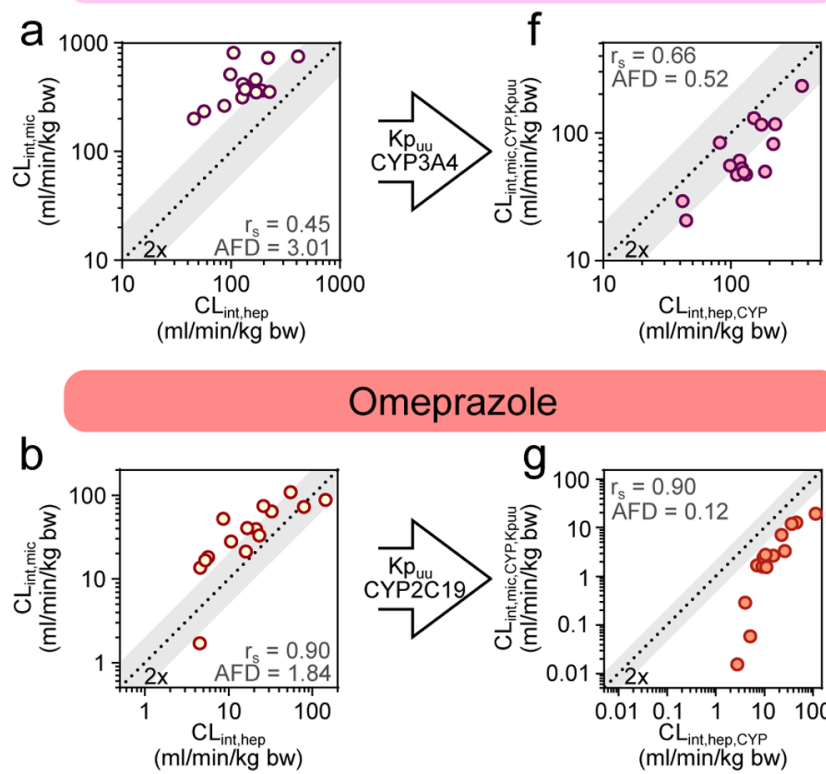

Omeprazole
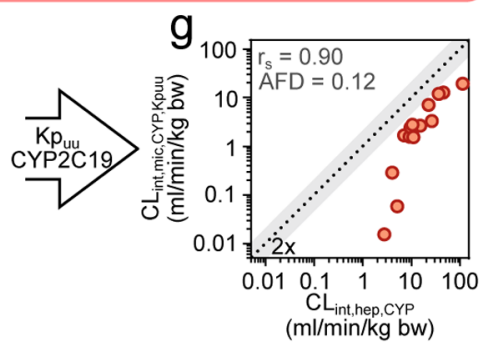

Diclofenac

C
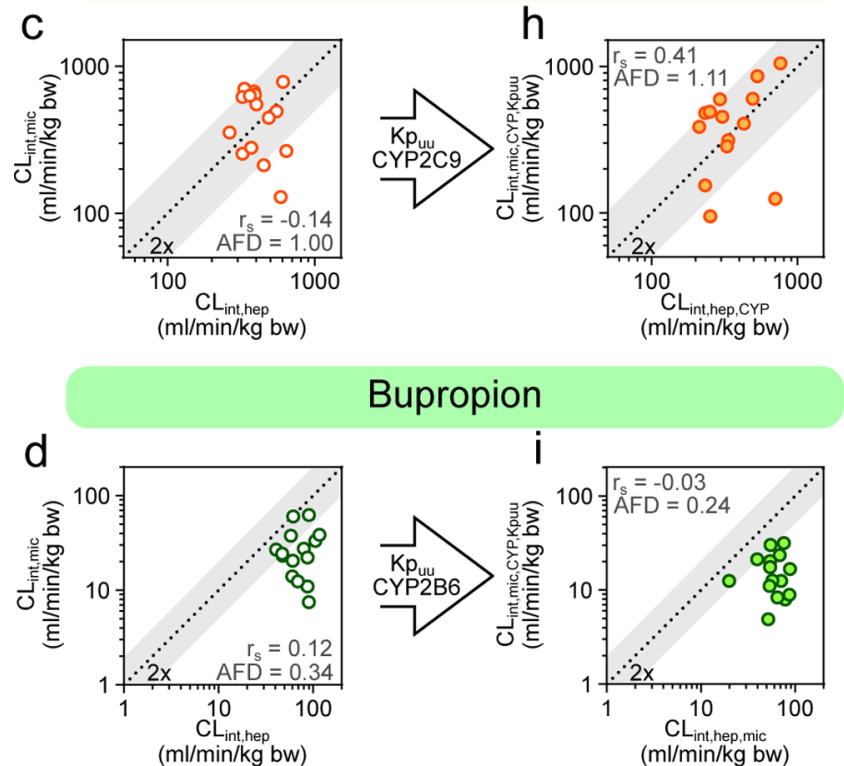

Bupropion
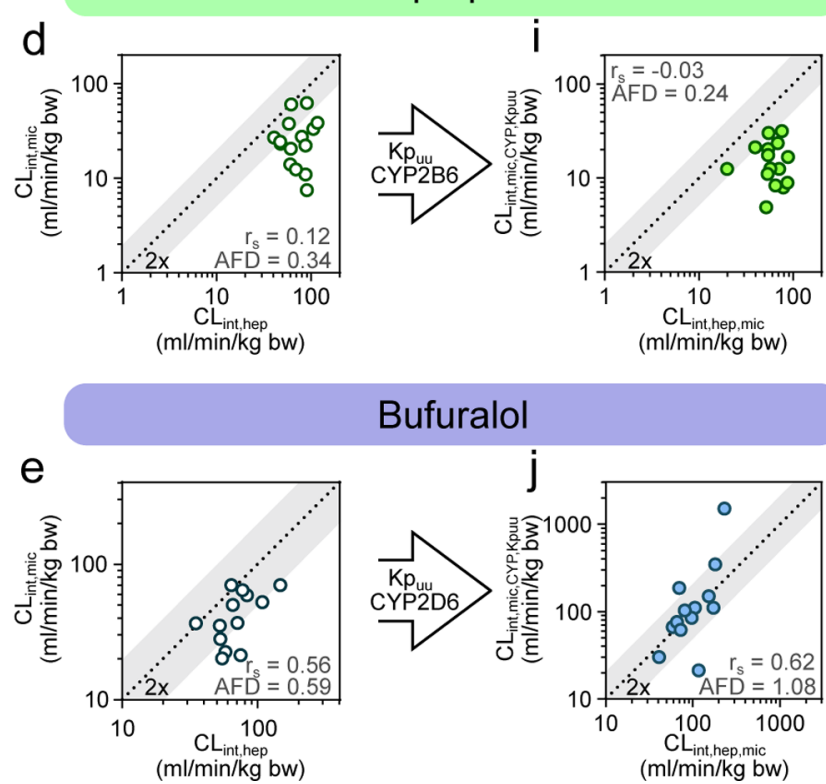

\section{Bufuralol}

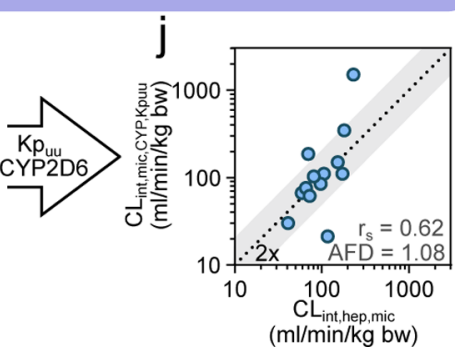

Figure 5. Adjustment of $\mathrm{CL}_{\text {int,mic }}$ and $\mathrm{CL}_{\text {int,hep }}$ with factors influencing metabolic clearance. (a-e) Intrinsic clearance of five probe CYP substrates (midazolam, omeprazole, diclofenac, bupropion, and bufuralol) measured in 15 donor-matched HLM and HH. Unbound
Figure 5. continued

in vitro clearance was scaled to $\mathrm{kg}$ body weight with eq 7. ( $\mathrm{f}-\mathrm{j})$ Intrinsic clearance of the five probe CYP substrates after adjustment of $\mathrm{Kp}_{\mathrm{uu}}$ and probe CYP amount in the respective system with eq 9. $r_{\mathrm{s}}=$ Spearman's rank correlation coefficient and AFD $=$ average fold difference. ${ }^{36}$

2.8 -fold). As the ER-associated proteins constituted $7 \%$ of the total protein content in our HL-assuming complete isolation and full recovery of the ER fraction in the HLM - we expected a 14-fold enrichment. The less-than-complete enrichment of ER-associated proteins was also reflected in a 2.2 to 4.6 -fold enrichment of the ER-membrane markers, CANX and POR, that is, similar or slightly lower than previous estimates (Figure S1i). ${ }^{16}$ The traditional ER-activity markers, glucose-6-phosphatase (G6PC) and HMG-CoA reductase (HMGCR), ${ }^{60}$ were also similarly enriched (3.4 to 7.4-fold) in the HLM (Figure $2 \mathrm{~g}$ ). Besides the ER-related proteins, we also found specific membrane markers for other organelles, for example, lysosomes, peroxisomes, and plasma membranes, in the HLM. These organelle marker proteins were enriched to a similar degree in our HLM, as shown previously with a targeted proteomics approach (Figure S1i) ${ }^{16}$ The pronounced variability in enrichment degree for different ER-related proteins ( 0.03 to 120 -fold) demonstrates the complexity of the enrichment process and limits the use of specific protein markers as scaling factors.

The lower-than-expected enrichment could have multiple reasons. First, proteins from other subcellular compartments in the HLM could have diluted the ER-related proteins. In agreement with previous observations, ${ }^{18}$ the HLM contained proportions of proteins from the mitochondria, nucleus, and cytosol comparable to what is in the whole-cell $\mathrm{HH}$ and $\mathrm{HL}$ samples. Presumably, nuclei, cell debris, and mitochondria originating from homogenized cells would be collected in the resulting "discard pellet," and thus lower proportions of these proteins would be found in the subsequent microsomal fractions obtained after centrifugation at $104,000 \mathrm{~g}$ for 60 min. ${ }^{43-46}$ Such separation of unwanted cell material was confirmed since the nuclear proteins constituted a smaller proportion of the total protein content of the HLM than that in both $\mathrm{HH}$ and HL (on average 19\% compared to 28 and $24 \%)$. Nonetheless, relatively large proportions of nuclear proteins contaminated the HLM and these nuclear proteins were not enriched in the discard pellet as commonly assumed. Rather, they were found in lower proportions than that in both $\mathrm{HL}$ and $\mathrm{HH}$ (20\% as compared to 28 and $24 \%$, respectively; Figure S1b). Furthermore, as mitochondria are divided into a heavy and a light fraction that sediment at $3000 \mathrm{~g}$ and 15,000 to $17,000 \mathrm{~g}$, respectively, ${ }^{45}$ it is non-trivial to achieve a complete separation of this organelle by centrifugation.

Second, ER-related proteins can be lost in the first low-speed centrifugation step, ${ }^{15,17}$ thereby reducing their enrichment in the microsome fraction. Our study supported this explanation since similar proportions of, for example, ER-related and plasma membrane proteins were found in the discard pellet from the first centrifugation step $(7400 \mathrm{~g}$ for $10 \mathrm{~min}$; Figure $\mathrm{S} 1 \mathrm{~b}, \mathrm{e}, \mathrm{g})$ as in the HH and HL. However, it cannot be ruled out that some fraction of the ER-related proteins in the discard pellet derives from residual intact cells, escaping the homogenization. $^{44,46}$ 
Finally, although "liver microsomes" is a well-established concept, there is a multitude of protocols available for the isolation process with varying number of steps, centrifugation speeds, and times. $8,12,26,43-46,61,62$ These inconsistencies in protocols most certainly contribute to the variable protein levels of CYP and UGT enzymes reported in the HLM fraction. ${ }^{63,64}$ Our study followed the same protocol HLM preparations as several other groups. ${ }^{26,27,65-69}$ We conclude that it is very difficult to completely separate subcellular components during differential centrifugation, and that lack of harmonization of centrifugation protocols contributes to differences between HLM preparations across studies. ${ }^{15-17}$ The incomplete separation of ER-localized drug metabolizing enzymes in the HLM preparations, and the contamination with proteins supposedly localized to other subcellular compartments, point to a need for improving and standardizing HLM preparation protocols while making use of advances in protein quantification. $^{70}$

Influence of Individual CYP Amount on Drug Metabolic $\mathrm{CL}_{\text {int }}$. Concentrations of CYP enzymes in the HLM from the 15 donors were comparable with, or higher than, previously reported concentrations in HLM (Figure S2a). ${ }^{19}$ However, the variable degree of enrichment for different enzymes and batches further complicates the use of MPPGL as a scaling factor for substrates that probe specific CYP enzymes. As the metabolic activity should be dependent on the amount of relevant CYP in the incubation, we hypothesized that the AFD and correlations between $\mathrm{CL}_{\text {int }}$ from HLM and $\mathrm{HH}$ would improve by taking into account the amount of specific CYP for each donor of the respective in vitro system.

Adjusting for CYP content improved the rank order correlations for three compounds (midazolam, diclofenac, and bufuralol) and remained unchanged at a high correlation level for omeprazole. This indicates that the specific CYP content partially compensated for the inter-individual variability. Surprisingly however, the absolute numerical agreement (AFD) between $\mathrm{HH}$ and HLM $\mathrm{CL}_{\text {int }}$ was only improved by adjusting for the CYP content for midazolam but not the other compounds. The systematically higher unadjusted $\mathrm{CL}_{\text {int }}$ for midazolam in HLM compared to $\mathrm{HH}(\mathrm{AFD}=2.95)$ was in agreement with the 3.5-fold higher levels of the probed CYP3A4 for HLM. This was reflected in the improved AFD (from 2.95 to 1.63 ) after adjusting the $\mathrm{CL}_{\text {int }}$ with CYP3A4 amount, instead of $\mathrm{mg}$ protein and million hepatocytes. For the other compounds, high CYP enzyme enrichment in the HLM was not reflected in proportionally higher $\mathrm{CL}_{\text {int }}$ (omeprazole, bufuralol, and bupropion), leading to over-compensation after adjusting for CYP content, and thus AFD was reduced below unity (Table 2; Table S3). In contrast, for diclofenac, the low enrichment of CYP2C9 in HLM led to higher AFD after adjusting for CYP content. A likely explanation is that the proteomics analysis measures the total amount of protein in the two systems; this might not always reflect activity. Thus, overall the compensation for specific CYP content improved correlations but in some cases introduced systematic offsets in $\mathrm{CL}_{\text {int }}$.

The correlations between bupropion $\mathrm{CL}_{\text {int,mic }}$ and CYP2B6 concentration $(r=0.33)$ and diclofenac $\mathrm{CL}_{\text {int,mic }}$ and CYP2C9 $(r=0.18)$, respectively, were lower than those observed earlier in HLM. ${ }^{71,72}$ This might explain why the $\mathrm{CL}_{\text {int }}$ predictions did not improve as much for these compounds as for midazolam. This contradiction in degree of correlation between $\mathrm{CL}_{\text {int }}$ and
CYP concentration could be because the two previous studies determined the $\mathrm{CL}_{\text {int }}$ based on formation rates of specific metabolites. In contrast, we used the commonly applied substrate depletion which includes the contribution of all possible metabolic pathways. ${ }^{33,73,74}$ For instance, for both omeprazole and bufuralol, $\mathrm{CL}_{\text {int }}$ values were relatively high for several donors despite low CYP2C19 or CYP2D6 protein concentrations in HLM and HH. Thus, the limited improvement in AFD after CYP adjustment-for the compounds other than midazolam-could be an effect of that multiple enzymes are involved in the metabolism. This would not be captured in our compensation for only the major CYP probe. For omeprazole, $\mathrm{CL}_{\text {int }}$ was only compensated for the amount of the main metabolizing enzyme CYP2C19, although this drug is also somewhat metabolized by CYP3A4 ${ }^{51}$ Similarly, bufuralol was only compensated for CYP2D6, while CYP2C19 also, to some extent, contribute to its metabolism. ${ }^{75}$ Likewise, diclofenac was only compensated for CYP2C9, while it is also metabolized by both CYP3A4 and UGT2B7. ${ }^{76}$ By monitoring all formed metabolites (e.g., diclofenac is metabolized to 3-,4-,5-, and acyl glucuronide diclofenac by the three enzymes ${ }^{77}$ ), the contribution of each enzyme to the drug's metabolism could be better defined and used to improve the activity-protein concentration correlations. In line with this, the $\mathrm{CL}_{\text {int }}$ for many of the compounds in this study correlated well with several non-probe CYP enzymes in both HLM and HH (Table S4; Figure S4). This further supports that additional enzymes may be involved in their metabolic clearance.

Intriguingly, other drug metabolizing enzymes were found at high levels in the HLMs, such as the ER-related protein groups, flavine-containing monooxygenases (FMOs) and UGTs, as well as cytosolic enzymes such as aldehyde dehydrogenases (ALDHs) and glutathione S-transferases (GSTs) (Figure S3ad; Supporting Information, Results). Although UGT enzymes were not activated with the cofactor UDPGA in these experiments, both GSTs and FMOs may be active in the HLM under these conditions. ${ }^{78,79}$ Both GSTs and FMOs metabolize a wide selection of different drug compounds. ${ }^{80-83}$ These enzymes could influence the metabolism of drugs in the HLM, and the possible contribution of these enzymes to the drug clearance warrants further investigation. This further complicates the scaling with specific CYP amount in the two systems.

Compensating the $\mathrm{CL}_{\text {int }}$ with Intracellular Concentrations. Intracellular unbound drug concentration has previously been used in: bridging differences between biochemical and cellular potency assays $\left(\mathrm{IC}_{50}\right) ;{ }^{21}$ predicting time-dependent CYP inhibition; ${ }^{22}$ and explaining differences in CYP enzyme inhibition in microsomes and hepatocytes. ${ }^{23}$ We therefore investigated whether $\mathrm{Kp}_{\mathrm{uu}}$ could also explain the observed system-dependent differences in metabolic $\mathrm{CL}_{\text {int }}$ of the five substrates. The hypothesis was that active transport and/or metabolic processes in intact hepatocytes could result in non-unity $\mathrm{Kp}_{\mathrm{uw}}$ that is, that more or less compound is available for metabolism in $\mathrm{HH}$ than in HLM. While $\mathrm{Kp}_{\mathrm{uu}}$ adjustment improved the systematic differences in CYP adjusted $\mathrm{CL}_{\text {int }}$ in HLM and $\mathrm{HH}$ for diclofenac and bufuralol (AFD improving from 1.56 to 1.11 and 0.42 to 1.08 ), it did not provide a satisfying explanation for the $\mathrm{CL}_{\text {int }}$ differences between HLM and $\mathrm{HH}$ for all five substrates. Previous successful applications of $\mathrm{Kp}_{\mathrm{uu}}{ }^{21-23}$ have assessed the intracellular exposure of molecules which were kept at relatively 
constant concentrations throughout the assay, for example, enzyme inhibitors or drugs with intracellular targets. In the present study, the constant metabolic removal of drug from the system likely shifted the ratio of intra-to-extracellular concentrations, to an extent depending on the relative rates of membrane passage and metabolic $\mathrm{CL}_{\text {int }}$. Unknown transport mechanisms could further shift the equilibrium, for example, diclofenac and midazolam may be substrates of efflux transporters. ${ }^{14,84,85}$ To overcome the limitations of membrane passage in hepatocytes, permeabilized hepatocytes might be an alternative for drug metabolism studies. ${ }^{86}$ However, the validity of these results in scaling to in vivo remains to be established.

\section{CONCLUSIONS}

In this study, we investigated the influence of specific protein amounts and intracellular unbound drug concentration ( $\left.\mathrm{Kp}_{\mathrm{uu}}\right)$ on the $\mathrm{CL}_{\text {int }}$ of prototypical probe substrates in HLM and $\mathrm{HH}$. To our knowledge, this is the first comparison of drug metabolic activity and global proteomic profiles in HLM and $\mathrm{HH}$ using matching donors.

We show systematic differences in the $\mathrm{CL}_{\text {int }}$ measured in donor-matched $\mathrm{HH}$ and HLM, demonstrating that such differences are not merely an effect of inter-individual variability. We outline important differences in the proteomic profiles in HL, HH, and HLM, indicating variable enrichment of supposedly ER-localized CYP enzymes in the preparation of HLM. This suggests that HLM may not equally and accurately capture hepatic metabolic capacity for all CYPs. Contamination of HLM with cytosolic-annotated enzymes is a further complication when using these systems to delineate complex metabolic pathways; it could also be that important drugmetabolizing enzymes are incorrectly annotated.

Together, our findings demonstrate that these factors do not provide a simple one-size-fits-all explanation for differences between HLM and HH. It is possible that these compounds are: metabolized by additional enzymes to the ones probed; that cycling of cellular CYP enzymes between active and inactive states complicates the application of measured protein concentrations; or that the non-steady-state nature of the metabolically competent system and/or saturation of active transport processes confounds the measurement of intracellular drug concentrations. These factors should be evaluated in the future to avoid the use of empirical scaling factors and improve predictions of drug metabolism.

\section{ASSOCIATED CONTENT}

\section{SI Supporting Information}

The Supporting Information is available free of charge at https://pubs.acs.org/doi/10.1021/acs.molpharmaceut.1c00053.

Supporting Information: Characteristics of the 15 liver donors; LC-MS/MS conditions in the compound quantification; kinetics and proteomics data for the 15 donors; correlation coefficients from $\mathrm{CL}_{\text {int }}$ of five probe substrates compared with CYP concentrations in HLM and $\mathrm{HH}$ from 15 donors; protein expression of CYPs, UGTs, FMOs, and cytosolic enzymes; metabolic activity and protein expression; drug accumulation and unbound fractions of drugs; metabolic clearance of midazolam, omeprazole, bupropion, diclofenac, and bufuralol; and adjusting $\mathrm{CL}_{\text {int,mic }}$ and $\mathrm{CL}_{\text {int,hep }}$ with factors influencing metabolic clearance (PDF)

Data S1: Global proteomics data of HH, HLM, HL, and discard pellet (XLSX)

Data S2: Bioinformatics results from global proteomics (XLSX)

\section{AUTHOR INFORMATION}

\section{Corresponding Author}

Per Artursson - Department of Pharmacy and Science for Life Laboratory, Uppsala University, 75237 Uppsala, Sweden; (1) orcid.org/0000-0002-3708-7395; Phone: +46-18 47144 71; Email: per.artursson@farmaci.uu.se

\section{Authors}

Christine Wegler - Department of Pharmacy, Uppsala University, 75237 Uppsala, Sweden; DMPK, Research and Early Development Cardiovascular, Renal and Metabolism, BioPharmaceuticals R\&D, AstraZeneca, 43150 Gothenburg, Sweden; 10 orcid.org/0000-0002-2810-7518

Pär Matsson - Department of Pharmacy, Uppsala University, 75237 Uppsala, Sweden; O orcid.org/0000-0002-90942581

Veronica Krogstad - Department of Pharmaceutical Biosciences, School of Pharmacy, University of Oslo, 0315 Oslo, Norway

Jozef Urdzik - Department of Surgical Sciences, Uppsala University, 75185 Uppsala, Sweden

Hege Christensen - Department of Pharmaceutical Biosciences, School of Pharmacy, University of Oslo, 0315 Oslo, Norway

Tommy B. Andersson - DMPK, Research and Early Development Cardiovascular, Renal and Metabolism, BioPharmaceuticals R\&D, AstraZeneca, 43150 Gothenburg, Sweden

Complete contact information is available at: https://pubs.acs.org/10.1021/acs.molpharmaceut.1c00053

\section{Notes}

The authors declare no competing financial interest.

The mass spectrometry proteomics data have been deposited to the ProteomeXchange Consortium via the PRIDE $^{87}$ partner repository with the data set identifier PXD014131.

\section{ACKNOWLEDGMENTS}

We thank André Mateus, Genome Biology Unit, EMBL, Heidelberg, Magnus Ölander and Andrea Treyer, Department of Pharmacy, Uppsala University, and Laura Hellinen, School of Pharmacy, University of Eastern Finland, for valuable discussions. This study was supported by the Swedish Research Council (approval numbers 5715, 01951, and 01586).

\section{REFERENCES}

(1) Brown, H. S.; Griffin, M.; Houston, J. B. Evaluation of Cryopreserved Human Hepatocytes as an Alternative in Vitro System to Microsomes for the Prediction of Metabolic Clearance. Drug Metab. Dispos. 2007, 35, 293.

(2) Di, L.; et al. Mechanistic insights from comparing intrinsic clearance values between human liver microsomes and hepatocytes to guide drug design. Eur. J. Med. Chem. 2012, 57, 441-448.

(3) Hakooz, N.; et al. Determination of a Human Hepatic Microsomal Scaling Factor for Predicting in Vivo Drug Clearance. Pharm. Res. 2006, 23, 533-539. 
(4) Obach, R. S. Prediction of Human Clearance of Twenty-Nine Drugs from Hepatic Microsomal Intrinsic Clearance Data: An Examination of In Vitro Half-Life Approach and Nonspecific Binding to Microsomes. Drug Metab. Dispos. 1999, 27, 1350.

(5) Riley, R. J.; McGinnity, D. F.; Austin, R. P. A unified model for predicting human hepatic, metabolic clearance from in vitro intrinsic clearance data in hepatocytes and microsomes. Drug Metab. Dispos. 2005, 33, 1304.

(6) Shah, P.; et al. An Automated High-Throughput Metabolic Stability Assay Using an Integrated High-Resolution Accurate Mass Method and Automated Data Analysis Software. Drug Metab. Dispos. 2016, 44, 1653-1661.

(7) Sohlenius-Sternbeck, A.-K.; et al. Evaluation of the human prediction of clearance from hepatocyte and microsome intrinsic clearance for 52 drug compounds. Xenobiotica 2010, 40, 637-649.

(8) Zhang, H.; et al. Content and activity of human liver microsomal protein and prediction of individual hepatic clearance in vivo. Sci. Rep. 2015, 5, 17671.

(9) Zhang, Z.; Tang, W. Drug metabolism in drug discovery and development. Acta Pharm. Sin. B 2018, 8, 721-732.

(10) Fardel, O.; et al. Evaluation of Drug Biliary Excretion Using Sandwich-Cultured Human Hepatocytes. Eur. J. Drug Metab. Pharmacokinet. 2019, 44, 13-30.

(11) Knights, K. M.; et al. In Vitro Drug Metabolism Using Liver Microsomes. Curr. Protoc. Pharmacol. 2016, 74, 7.8.1-7.8.24.

(12) Palade, G. E.; Siekevitz, P. Liver microsomes. J. Biophys. Biochem. Cytol. 1956, 2, 171.

(13) Williamson, B.; Harlfinger, S.; McGinnity, D. F. Evaluation of the Disconnect between Hepatocyte and Microsome Intrinsic Clearance and In Vitro In Vivo Extrapolation Performance. Drug Metab. Dispos. 2020, 48, 1137.

(14) Keefer, C.; et al. Mechanistic insights on clearance and inhibition discordance between liver microsomes and hepatocytes when clearance in liver microsomes is higher than in hepatocytes. Eur. J. Pharm. Sci. 2020, 155, 105541.

(15) Wiśniewski, JR; Wegler, C.; Artursson, P. Subcellular fractionation of human liver reveals limits in global proteomic quantification from isolated fractions. Anal. Biochem. 2016, 509, 8288.

(16) Xu, M.; et al. Targeted LC-MS/MS Proteomics-Based Strategy To Characterize in Vitro Models Used in Drug Metabolism and Transport Studies. Anal. Chem. 2018, 90, 11873-11882.

(17) Harwood, M. D.; et al. Lost in Centrifugation: Accounting for Transporter Protein Losses in Quantitative Targeted Absolute Proteomics. Drug Metab. Dispos. 2014, 42, 1766.

(18) Achour, B.; et al. Global Proteomic Analysis of Human Liver Microsomes: Rapid Characterization and Quantification of Hepatic Drug-Metabolizing Enzymes. Drug Metab. Dispos. 2017, 45, 666.

(19) Couto, N.; et al. Quantification of Proteins Involved in Drug Metabolism and Disposition in the Human Liver Using Label-Free Global Proteomics. Mol. Pharm. 2019, 16, 632-647.

(20) Mateus, A.; et al. Intracellular drug bioavailability: a new predictor of system dependent drug disposition. Sci. Rep. 2017, 7, 43047.

(21) Mateus, A.; et al. Prediction of intracellular exposure bridges the gap between target- and cell-based drug discovery. Eur. J. Pharm. Sci. 2017, 114, No. E6231.

(22) Filppula, A. M.; et al. Improved predictions of time-dependent drug-drug interactions by determination of cytosolic drug concentrations. Sci. Rep. 2019, 9, 5850.

(23) Treyer, A.; et al. Impact of Intracellular Concentrations on Metabolic Drug-Drug Interaction Studies. AAPS J. 2019, 21, 77.

(24) LeCluyse, E. L.; Alexandre, E. Isolation and Culture of Primary Hepatocytes from Resected Human Liver Tissue. In Hepatocytes: Methods and Protocols; Maurel, P., Ed.; Humana Press: Totowa, NJ, 2010; Vol. 640, pp 57-82.

(25) Ölander, M.; et al. A simple approach for restoration of differentiation and function in cryopreserved human hepatocytes. Arch. Toxicol. 2019, 93, 819-829.
(26) Hermann, M.; et al. Evaluation of microsomal incubation conditions on CYP3A4-mediated metabolism of cyclosporine A by a statistical experimental design. Curr. Drug Metab. 2006, 7, 265-271.

(27) Krogstad, V.; et al. A Comparative Analysis of Cytochrome P450 Activities in Paired Liver and Small Intestinal Samples from Patients with Obesity. Drug Metab. Dispos. 2020, 48, 8.

(28) Wiśniewski, J. R.; Mann, M. Consecutive Proteolytic Digestion in an Enzyme Reactor Increases Depth of Proteomic and Phosphoproteomic Analysis. Anal. Chem. 2012, 84, 2631-2637.

(29) Wiśniewski, J. R.; Gaugaz, F. Z. Fast and Sensitive Total Protein and Peptide Assays for Proteomic Analysis. Anal. Chem. 2015, 87, $4110-4116$

(30) Tyanova, S.; Temu, T.; Cox, J. The MaxQuant computational platform for mass spectrometry-based shotgun proteomics. Nat. Protoc. 2016, 11, 2301

(31) Huber, W.; et al. Variance stabilization applied to microarray data calibration and to the quantification of differential expression. Bioinformatics 2002, 18, S96-S104.

(32) Wiśniewski, J. R.; Rakus, D. Multi-enzyme digestion FASP and the 'Total Protein Approach'-based absolute quantification of the Escherichia coli proteome. J. Proteomics 2014, 109, 322-331.

(33) Jones, H. M.; Houston, J. B. Substrate depletion approach for determining in vitro metabolic clearance: time dependencies in hepatocyte and microsomal incubations. Drug Metab. Dispos. 2004, 32, 973.

(34) Gillen, C. M.; Forbush, B., Iii Functional interaction of the K-Cl cotransporter (KCC1) with the Na-K-Cl cotransporter in HEK-293 cells. Am. J. Physiol.: Cell Physiol. 1999, 276, C328-C336.

(35) Andersson, T. B.; et al. An assessment of human liver-derived in vitro systems to predict the in vivo metabolism and clearance of almokalant. Drug Metab. Dispos. 2001, 29, 712-720.

(36) Tang, $\mathrm{H}$.; et al. Interspecies Prediction of Human Drug Clearance Based on Scaling Data from One or Two Animal Species. Drug Metab. Dispos. 2007, 35, 1886.

(37) Tyanova, S.; et al. The Perseus computational platform for comprehensive analysis of (prote)omics data. Nat. Methods 2016, 13, 731.

(38) Huang, D. W.; Sherman, B. T.; Lempicki, R. A. Systematic and integrative analysis of large gene lists using DAVID bioinformatics resources. Nat. Protoc. 2008, 4, 44.

(39) Liebermeister, W.; et al. Visual account of protein investment in cellular functions. Eur. J. Pharm. Sci. 2014, 111, 8488.

(40) Thul, P. J.; et al. A subcellular map of the human proteome. Science 2017, 356, No. eaal3321.

(41) Lipscomb, J. C.; et al. In vitro to in vivo extrapolation for trichloroethylene metabolism in humans. Toxicol. Appl. Pharmacol. 1998, 152, 376-387.

(42) Guengerich, F. P.; et al. Measurement of cytochrome P450 and NADPH-cytochrome P450 reductase. Nat. Protoc. 2009, 4, 12451251.

(43) Alberts, B.; et al. Fractionation of Cells. Molecular Biology of the Cell, 4th ed.; Garland Science, 2002.

(44) Andringa, K. K.; Bailey, S. M., Detection of protein thiols in mitochondrial oxidative phosphorylation complexes and associated proteins. In Methods in Enzymology; Cadenas, E., Packer, L., Eds.; Academic Press, 2010; Vol. 474, pp 83-108.

(45) Graham, J. Preparation of Crude Subcellular Fractions by Differential Centrifugation; The Scientific World Journal, 2002; Vol. 2.

(46) Lodish, H.; et al. Purification of Cells and Their Parts. Molecular Cell Biology, 4th ed.; WH Freeman, 2000.

(47) Zanger, U. M.; Schwab, M. Cytochrome P450 enzymes in drug metabolism: Regulation of gene expression, enzyme activities, and impact of genetic variation. Pharmacol. Ther. 2013, 138, 103-141.

(48) Wegler, C.; et al. Variability in Mass Spectrometry-based Quantification of Clinically Relevant Drug Transporters and Drug Metabolizing Enzymes. Mol. Pharm. 2017, 14, 3142-3151.

(49) Wiśniewski, JR; et al. In-depth quantitative analysis and comparison of the human hepatocyte and hepatoma cell line HepG2 proteomes. J. Proteomics 2016, 136, 234-47. 
(50) Weiß, F.; et al. Direct Quantification of Cytochromes P450 and Drug Transporters-A Rapid, Targeted Mass Spectrometry-Based Immunoassay Panel for Tissues and Cell Culture Lysates. Drug Metab. Dispos. 2018, 46, 387-396.

(51) Äbelö, A.; et al. Stereoselective Metabolism of Omeprazole by Human Cytochrome P450 Enzymes. Drug Metab. Dispos. 2000, 28, 966.

(52) Foster, J. A.; Houston, J. B.; Hallifax, D. Comparison of intrinsic clearances in human liver microsomes and suspended hepatocytes from the same donor livers: clearance-dependent relationship and implications for prediction of in vivo clearance. Xenobiotica 2011, 41, 124-136.

(53) $\mathrm{Lu}, \mathrm{C}$; ; et al. Comparison of intrinsic clearance in liver microsomes and hepatocytes from rats and humans: evaluation of free fraction and uptake in hepatocytes. Drug Metab. Dispos. 2006, 34, $1600-1605$.

(54) Stringer, R.; Nicklin, P. L.; Houston, J. B. Reliability of human cryopreserved hepatocytes and liver microsomes as in vitro systems to predict metabolic clearance. Xenobiotica 2008, 38, 1313-1329.

(55) Houston, B. J. Utility of in vitro drug metabolism data in predicting in vivo metabolic clearance. Biochem. Pharmacol. 1994, 47, 1469-1479.

(56) Barter, Z.; et al. Scaling factors for the extrapolation of in vivo metabolic drug clearance from in vitro data: reaching a consensus on values of human micro-somal protein and hepatocellularity per gram of liver. Curr. Drug Metab. 2007, 8, 33-45.

(57) Lipscomb, J. C.; et al. Variance of Microsomal Protein and Cytochrome P450 2E1 and 3A Forms in Adult Human Liver. Toxicol. Mech. Methods 2003, 13, 45-51.

(58) Wilson, Z. E.; et al. Inter-individual variability in levels of human microsomal protein and hepatocellularity per gram of liver. $\mathrm{Br}$. J. Clin. Pharmacol. 2003, 56, 433-440.

(59) Stanger, B. Z. Cellular homeostasis and repair in the mammalian liver. Annu. Rev. Physiol. 2015, 77, 179-200.

(60) Hamilton, R. L.; et al. A rapid calcium precipitation method of recovering large amounts of highly pure hepatocyte rough endoplasmic reticulum. J. Lipid Res. 1999, 40, 1140-1147.

(61) Boobis, A.; et al. Monooxygenase activity of human liver in microsomal fractions of needle biopsy specimens. Br. J. Clin. Pharmacol. 1980, 9, 11-19.

(62) Hayes, K. A.; et al. In vivo disposition of caffeine predicted from hepatic microsomal and hepatocyte data. Drug Metab. Dispos. 1995, 23, 349.

(63) Achour, B.; Rostami-Hodjegan, A.; Barber, J. Protein expression of various hepatic uridine 5 -diphosphate glucuronosyltransferase (UGT) enzymes and their inter-correlations: a meta-analysis. Biopharm. Drug Dispos. 2014, 35, 353-361.

(64) Achour, B.; Barber, J.; Rostami-Hodjegan, A. Expression of Hepatic Drug-Metabolizing Cytochrome P450 Enzymes and Their Intercorrelations: A Meta-Analysis. Drug Metab. Dispos. 2014, 42, 1349.

(65) Carlile, D. J.; et al. Microsomal prediction of in vivo clearance of CYP2C9 substrates in humans. Br. J. Clin. Pharmacol. 1999, 47, 625-635.

(66) Ashforth, E. I.; et al. Prediction of in vivo disposition from in vitro systems: clearance of phenytoin and tolbutamide using rat hepatic microsomal and hepatocyte data. J. Pharmacol. Exp. Ther. 1995, 274, 761.

(67) Naritomi, Y.; et al. Prediction of Human Hepatic Clearance from in Vivo Animal Experiments and in Vitro Metabolic Studies with Liver Microsomes from Animals and Humans. Drug Metab. Dispos. 2001, 29, 1316.

(68) Ernster, L.; Siekevitz, P.; Palade, G. E. Enzyme-structure relationships in the endoplasmic reticulum of rat liver: A Morphological and Biochemical Study. J. Cell Biol. 1962, 15, 541562.

(69) Andersson, T. B.; et al. An evaluation of the in vitro metabolism data for predicting the clearance and drug-drug interaction potential of CYP2C9 substrates. Drug Metab. Dispos. 2004, 32, 715.
(70) Prasad, B.; et al. Toward a Consensus on Applying Quantitative Liquid Chromatography-Tandem Mass Spectrometry Proteomics in Translational Pharmacology Research: A White Paper. Clin. Pharmacol. Ther. 2019, 106, 525-543.

(71) Ohtsuki, S.; et al. Simultaneous Absolute Protein Quantification of Transporters, Cytochromes P450, and UDP-Glucuronosyltransferases as a Novel Approach for the Characterization of Individual Human Liver: Comparison with mRNA Levels and Activities. Drug Metab. Dispos. 2012, 40, 83.

(72) Jamwal, R.; et al. Multiplex and Label-Free Relative Quantification Approach for Studying Protein Abundance of Drug Metabolizing Enzymes in Human Liver Microsomes Using SWATHMS. J. Proteome Res. 2017, 16, 4134-4143.

(73) Nath, A.; Atkins, W. M. A Theoretical Validation of the Substrate Depletion Approach to Determining Kinetic Parameters. Drug Metab. Dispos. 2006, 34, 1433.

(74) Obach, R. S.; Reed-Hagen, A. E. Measurement of Michaelis Constants for Cytochrome P450-Mediated Biotransformation Reactions Using a Substrate Depletion Approach. Drug Metab. Dispos. 2002, 30, 831.

(75) Mankowski. The Role of CYP2C19 in the Metabolism of (+/-) Bufuralol, the Prototypic Substrate of CYP2D6. Drug Metab. Dispos. 1999, 27, 1024-1028.

(76) Lazarska, K. E.; et al. Effect of UGT2B7*2 and CYP2C8*4 polymorphisms on diclofenac metabolism. Toxicol. Lett. 2018, 284, $70-78$.

(77) Boerma, J. S.; Vermeulen, N. P. E.; Commandeur, J. N. M. One-electron oxidation of diclofenac by human cytochrome P450s as a potential bioactivation mechanism for formation of $2^{\prime}$-(glutathion-Syl)-deschloro-diclofenac. Chem.-Biol. Interact. 2014, 207, 32-40.

(78) Aniya, Y.; Shimoji, M.; Naito, A. Increase in liver microsomal glutathione S-transferase activity by phenobarbital treatment of rats: Possible involvement of oxidative activation via cytochrome $\mathrm{P} 450$. Biochem. Pharmacol. 1993, 46, 1741-1747.

(79) Fisher, M. B.; et al. Flavin-Containing Monooxygenase Activity in Hepatocytes and Microsomes: In Vitro Characterization and In Vivo Scaling of Benzydamine Clearance. Drug Metab. Dispos. 2002, 30, 1087.

(80) Wormhoudt, L. W.; Commandeur, J. N. M.; Vermeulen, N. P. E. Genetic Polymorphisms of Human N-Acetyltransferase, Cytochrome P450, Glutathione-S-Transferase, and Epoxide Hydrolase Enzymes: Relevance to Xenobiotic Metabolism and Toxicity. Crit. Rev. Toxicol. 1999, 29, 59-124.

(81) Wu, B.; Dong, D. Human cytosolic glutathione transferases: structure, function, and drug discovery. Trends Pharmacol. Sci. 2012, $33,656-668$.

(82) Krueger, S. K.; Williams, D. E. Mammalian flavin-containing monooxygenases: structure/function, genetic polymorphisms and role in drug metabolism. Pharmacol. Ther. 2005, 106, 357-387.

(83) Phillips, I. R.; Shephard, E. A. Drug metabolism by flavincontaining monooxygenases of human and mouse. Expert Opin. Drug Metab. Toxicol. 2017, 13, 167-181.

(84) Lagas, J. S.; et al. Transport of Diclofenac by Breast Cancer Resistance Protein (ABCG2) and Stimulation of Multidrug Resistance Protein 2 (ABCC2)-Mediated Drug Transport by Diclofenac and Benzbromarone. Drug Metab. Dispos. 2009, 37, 129.

(85) Takano, M.; et al. Interaction with P-glycoprotein and transport of erythromycin, midazolam and ketoconazole in Caco-2 cells. Eur. J. Pharmacol. 1998, 358, 289-294.

(86) Geelen, M. J. H. The use of digitonin-permeabilized mammalian cells for measuring enzyme activities in the course of studies on lipid metabolism. Anal. Biochem. 2005, 347, 1-9.

(87) Perez-Riverol, Y.; et al. The PRIDE database and related tools and resources in 2019: improving support for quantification data. Nucleic Acids Res. 2019, 47, D442-D450. 